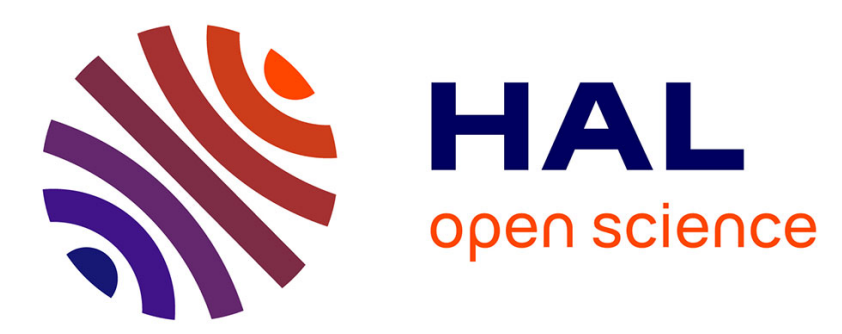

\title{
Acridinium Salts and Cyanoarenes as Powerful Photocatalysts: Opportunities in Organic Synthesis
} Anis Tlili, Sami Lakhdar

\section{To cite this version:}

Anis Tlili, Sami Lakhdar. Acridinium Salts and Cyanoarenes as Powerful Photocatalysts: Opportunities in Organic Synthesis. Angewandte Chemie International Edition, 2021, 60 (36), pp.19526-19549. 10.1002/anie.202102262 . hal-03394556

\section{HAL Id: hal-03394556 https://hal.science/hal-03394556}

Submitted on 22 Oct 2021

HAL is a multi-disciplinary open access archive for the deposit and dissemination of scientific research documents, whether they are published or not. The documents may come from teaching and research institutions in France or abroad, or from public or private research centers.
L'archive ouverte pluridisciplinaire HAL, est destinée au dépôt et à la diffusion de documents scientifiques de niveau recherche, publiés ou non, émanant des établissements d'enseignement et de recherche français ou étrangers, des laboratoires publics ou privés. 


\section{Acridinium Salts and Cyanoarenes as Powerful Photocatalysts:}

\section{Opportunities in Organic Synthesis}

Anis Tlili, ${ }^{*[a]}$ and Sami Lakhdar ${ }^{*[b]}$

Dedicated to the memory of Prof. Dr. Rolf Huisgen (1920-2020)

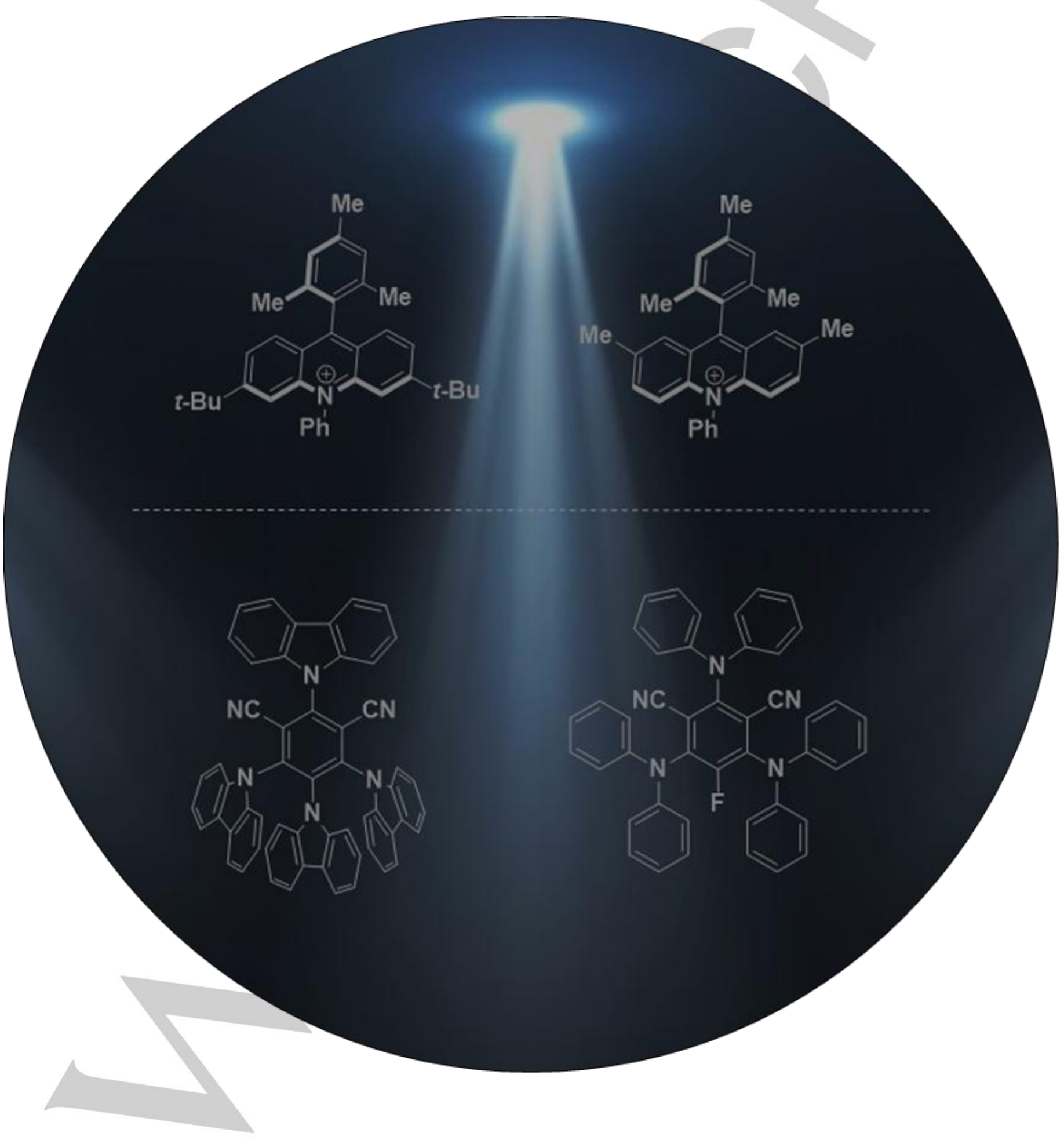

[a] Dr. A. Tlili

Institute of Chemistry and Biochemistry (ICBMS-UMR CNRS 5246) 
Univ Lyon, Université Lyon 1, CNRS, CPE-Lyon, INSA

43 Bd du 11 Novembre 1918, 69622 Villeurbanne, France

E-mail: anis.tlili@univ-lyon1.fr

[b] Dr. S. Lakhdar

CNRS/Université Toulouse III - Paul Sabatier,

Laboratoire Hétérochimie Fondamentale et Appliquée, LHFA UMR 5069,

118 Route de Narbonne, 31062 Toulouse Cedex 09, France

E-mail: lakhdar@chimie.ups-tlse.fr

Abstract: The use of organic photocatalysts has revolutionized the field of photoredox catalysis as it allowed access to new reactivities that were traditionally restricted to transition metal photocatalysts. In this review we focus our attention onto two classes of organophotocatalysts, namely acridinium ions and cyanoarenes derivatives that have demonstrated remarkable activities in large variety of organic transformations. Specifically, the use of those photocatalysts in oxidative quenching processes will be discussed with a special focus on their mechanistic aspects.

\section{Introduction}

"Light is life. It's as simple as that". It was with those words that the 1999 Chemistry Nobel Laureate Ahmed Zewail summarized the impact of light in many facets of our daily life. ${ }^{[1]}$ For instance, the conversion of light into electrical energy (photovoltaics) or the storage of solar light continue to be at the forefront of technology across numerous domains. ${ }^{[2]}$ The impact of light to trigger redox transformations has also been recognized a century ago by the visionary chemist Giacomo Ciamcian who suggested developing technologies that permit the conversion of light into chemicals and fuels. ${ }^{[3]}$ Surprisingly, this research area has not seen the same interest and development compared to photovoltaics and energy storage. Recently, visible light photoredox catalysis has experienced renewed interest and the importance of light to form chemical bonds under mild conditions became of high importance. ${ }^{[4]}$ In this regard, a plethora of reactions have been developed including the synthesis of complex molecules. ${ }^{[4 n]}$ Owing to the high redox potentials as well as the relatively long-lifetime of their excited states, iridium- and ruthenium based photocatalysts are traditionally employed in many of those photoreactions. In fact, by a simple modification of the ligand structure, the photophysical and electrochemical properties of the photocatalysts can be controlled. ${ }^{[4]]}$

Although commercially available organic dyes such as Eosin $Y^{[5]}$, and Flavins ${ }^{[6]}$ have shown interesting photochemical properties as photocatalysts, molecular scaffold variation is often complicated, which prevent the use of structurally related photocatalysts with different photochemical properties. In order to fill this gap and to provide purely organic, cheaper, sustainable, and environmentally benign photocatalysts, efforts have recently focused on designing practically simple and modulable syntheses to access new and efficient organophotocatalysts. ${ }^{[7]}$ In this context, various structures have emerged including highly oxidizing and reducing catalysts, which have successfully been applied in the activation of inert chemical bonds. Thus, opening new avenues for the development of challenging chemical transformations under mild conditions.

Though seminal reviews covered the field of organophotocatalysis, the use of new variants of acridinium salts $^{[8,9]}$ and cyanoarenes ${ }^{[10]}$, which have recently emerged as powerful photocatalysts, has not been reported into detail from synthetic and mechanitic point of view.

This review focuses on the recent developments in this area by discussing the reactivity of acridinium salts and cyanoarenes, which have shown remarkable reactivity in photoredox catalysis. As depicted in Scheme 1, both photocatalysts types (PC) absorb light to reach excited states from which they can oxidize a given substrate $(S)$ to generate an opened-shell species along with the reduced form of the photocatalyst. The former can then be involved in various organic transformation, thus forming carboncarbon and carbon-heteroatom bonds.

Furthermore, recent synthetic studies have demonstrated the ability to tune the photophysical and electrochemical properties of those catalysts by tailoring their structures.

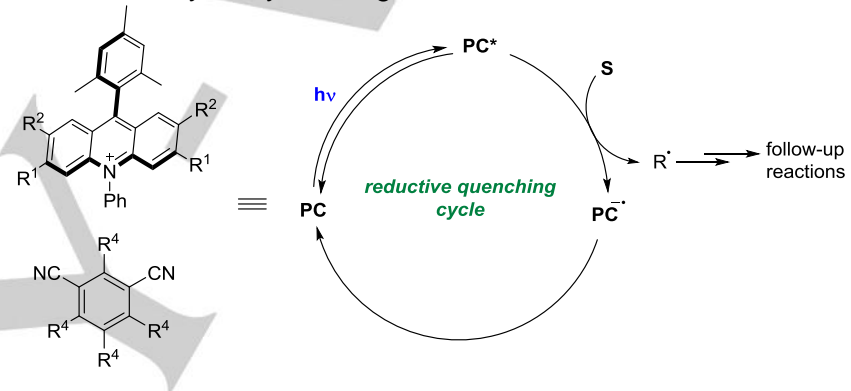

Scheme 1. Scope of the review

Anis Tlili is CNRS Research Fellow. After studying chemistry in the Université de Bourgogne, Anis gained a master's degree in the same university with Prof. S. Jugé (Dijon, France). Afterwards, he completed his PhD in the group of Dr. M. Taillefer (Montpellier, France) in late 2011 Subsequently, he joined the group of Prof. M. Beller (LIKAT, Rostock Germany) for a postdoctoral stay before taking up a second collaborative postdoctoral position (CEA/ICSN, Paris). In 2014 he was appointed a CNRS research Fellow in Lyon. His current research interests lie in the area of homogeneous catalysis/photoredox catalysis, with particular focus on fluorine chemistry. Anis was awarded recently a JSP Fellow for the 53rd Bürgenstock and was selected to participate to EuChems young investigators workshop 2018 in Oxford. 
Sami Lakhdar received his Ph.D. in 2006 from the University of Versailles and the University of Monastir under the supervision of Prof. François Terrier and Prof. Taoufik Boubaker. In 2007, he joined the group of Prof. Herbert Mayr at the Ludwig Maximilians University (LMU) (Germany) as an Alexander von Humboldt Postdoctoral Fellow, working on reaction mechanisms of organocatalyzed reactions. Since 2013, he is a CNRS Associate Researcher (20132019 (LCMT, Caen) and from 2020 he is a group leader at LHFA (Toulouse). His research interests focus on organic reactivity and visiblelight-mediated carbon-heteroatom bond-forming reactions. Sami received the Jean-Pierre Sauvage award from the Organic Chemistry Division of the French Chemical Society (2019), the Thieme Chemistry journal award (2013), and the Römer award for postdoctoral research of the Dr. Klaus Römer Foundation (2011).

\section{Acridinium based organophotocatalysts}

\subsection{Introduction}

Although the use of acridinium ions as photocatalysts was reported a while ago, they received little attention due to their tendency to undergo nucleophilic addition at the 9-position. The limitation of nucleophilic addition has been addressed in 2004 by Fukuzumi et al. Indeed, the synthesis of an acridinium ion (9mesityl-10-methylacridinium ion) has been reported, bearing a mesityl group at the 9-position (Scheme 2). ${ }^{[1,12]}$ This new photocatalyst has shown remarkable photoreactivity in numerous transformations. The key to success was attributed to the ability of this salt to access a charge transfer state through an electron transfer between the mesityl (donor) and the acridinium (acceptor). ${ }^{[13]}$ In fact, due to the orthogonality between the donor and the acceptor moieties, photoinduced electron transfer from the mesitylene to the singlet excited state of the acridinium gives rise to the formation of $\left(\mathrm{Acr}^{\bullet}-\mathrm{Mes}^{\bullet+}\right)$ state Apart from the slow intramolecular back electron transfer of this state, its high oxidation potential $(+2.18 \mathrm{~V} v s \mathrm{SCE})$ makes it one of the most oxidizing organophotocatalysts. ${ }^{[11]}$ Indeed, this catalyst has shown efficiency to oxidize alkenes and arenes, thus enabling the functionalization of various organic molecules under metal-free conditions. ${ }^{[14,15,16,17,18,19]}$ This has nicely been demonstrated by the pioneering work of Fukuzumi and more recently further explored by the group of Nicewicz for a large variety of organic transformations, especially hydrofunctionalization of alkenes. However, it was noticed that the reactivity of this photocatalyst can be inhibited by $I$ ) nucleophilic and radical addition at 2,7 or 3,6-positions ${ }^{[20]}$, and ii) $\mathrm{N}$-demethylation, which are responsible for the deactivation of the photocatalyst. ${ }^{[21]}$ These problems were elegantly addressed by incorporating bulky substituents at the $2-$ and 7-positions or at the 3- and 6-positions and a phenyl group at the nitrogen atom. ${ }^{[20]}$ In this regard, Mes-(3,6-tBu-Acr)- $\mathrm{Ph}^{+}$(PC2) turned out to be the catalyst of choice due to the robustness and the similar electrochemical properties to the Fukuzumi catalyst it offers (Scheme 2).

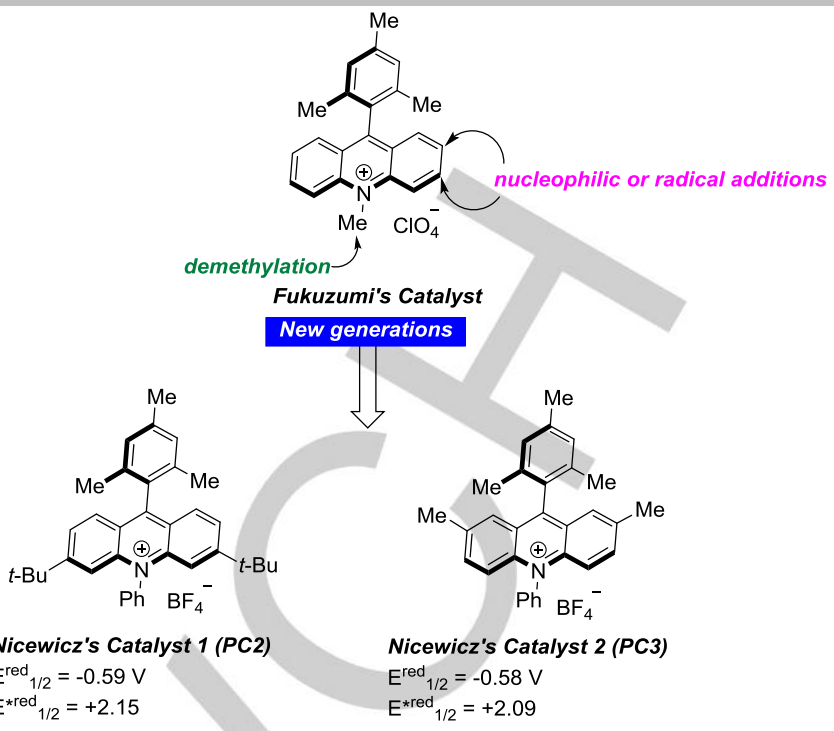

Scheme 2. Fukuzumi's and Nicewicz's catalysts

\subsection{Nicewicz's photocatalysts for the activation of inert bonds}

\subsubsection{Oxidation of arenes}

The arene $\mathrm{C}-\mathrm{H}$ amination with heterocyclic derivatives was reported in 2015 by the group of Nicewicz. ${ }^{[22]}$ When PC2 was employed under blue LEDs irradiation, para-selective $\mathrm{C}-\mathrm{N}$ bond formation was achieved. The reactions were performed in the presence of catalytic amount of TEMPO as a co-catalyst (20 mol\%) and $\mathrm{O}_{2}$ as a terminal oxidant. High functional group tolerance, including free alcohols, amides, esters, silyl ethers, halides, alkenes and protected amines was demonstrated. The reactions were performed with a slight excess of the heterocyclic compounds (1.25 to 2 equiv.) in DCE as solvent at $33{ }^{\circ} \mathrm{C}$ (Scheme 3). It should be mentioned that the use of ammonia as a nucleophile enabled the access to free anilines.

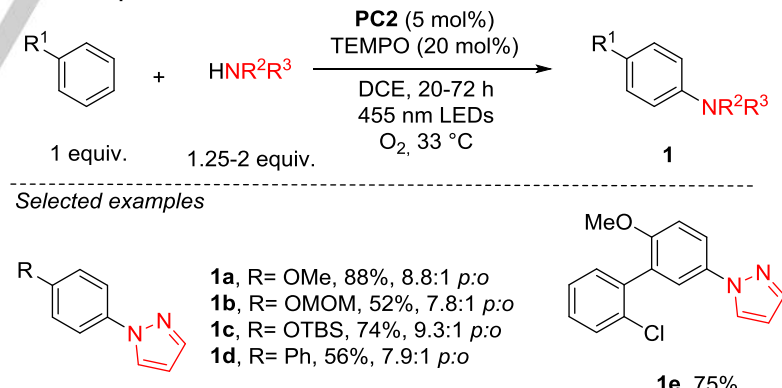

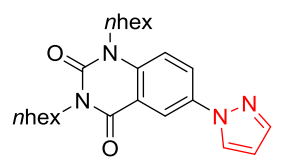

1f, $43 \%,>15: 1$ regioselectivity<smiles>COc1ccc(-n2cncc2CC(C(C)=O)N(C)C(C)(C)C)cc1</smiles>

1g, $43 \%$
$1 \mathrm{~h}, 52 \%$ 1.2:1 N3 (5:1):N1 (8:1)<smiles>COc1cc(CNC(=O)CCCC/C=C/C(C)(C)C)c(-n2cccn2)cc1OC(C)=O</smiles>

1i, $66 \%$<smiles>COc1ccc2cc(C(C)(C)C(=O)O)ccc2c1-n1cccn1</smiles>

1j, $26 \%$
Scheme 3. Arenes $\mathrm{C}-\mathrm{H}$ amination developed by the group of Nicewicz. MOM methoxymethyl acetal, TBS: tert-butyldimethylsilyl. 
The postulated reaction mechanism relies on the formation of an arene radical cation, formed through the oxidation of the arene by the excited PC2. Due to its high electrophilicity, the radical cation can react with the heterocyclic compound to form after deprotonation the cyclohexadienyl radical intermediate $\mathbf{A}$ (Scheme 3). TEMPO was suggested to aromatize this intermediate by hydrogen atom abstraction to offer the desired product. According to a previously reported Fukuzumi study, the photocatalyst is regenerated through reduction of $\mathrm{O}_{2}$ by the acridine radical. The generated superoxide $\mathrm{O}_{2}{ }^{\bullet-}$ serves as HAT abstractor to regenerate the TEMPO (Scheme 4).

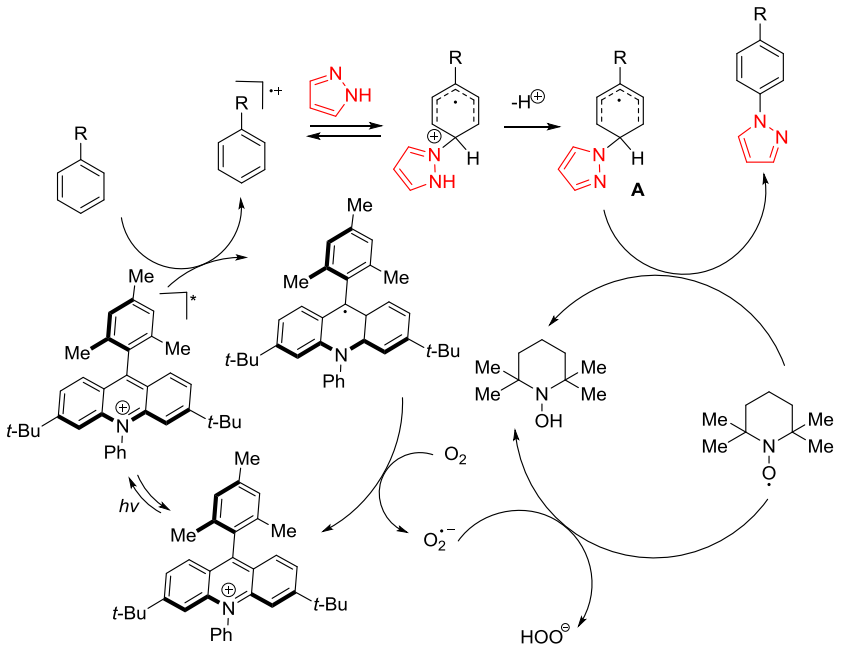

Scheme 4. Proposed mechanism for the $\mathrm{C}-\mathrm{H}$ amination of arenes developed by the group of Nicewicz.

To rationalize the high selectivity, Nicewicz et al. proposed a computational predictive model to understand the site-selective aryl and heteroaryl $\mathrm{C}-\mathrm{H}$ functionalization. ${ }^{[23]}$ In this model, five factors should be considered: $i$ ) the oxidation of the aromatic system by the acridinium photocatalyst; ii) the electrophilicity of the generated radical cation; iii) the representation of the radical cation as a delocalized or localized distonic radical cation; iv) the change in spin density when going from arene to the corresponding radical cation; and $v$ ) the electronic nature and position of the substituents. ${ }^{[23]}$

This interesting strategy was employed by $\mathrm{Li}$ and Nicewicz for the direct fluorination of aromatic $\mathrm{C}-\mathrm{H}$ bonds using radioactive ${ }^{18} \mathrm{~F} .{ }^{[24]}$ The protocol requires $\mathrm{PC2}$ as the photocatalyst, tetrabutylammonium $-{ }^{18} \mathrm{~F}$ as fluoride source, and TEMPO and air as oxidants under blue laser $(450 \mathrm{~nm})$ irradiation for 30 to 60 min (Scheme 5). The radiochemical yields (RCYs) ranges from 5 to $50 \%$ and various functional groups such as halides, ketones, esters, and nitriles were tolerated.

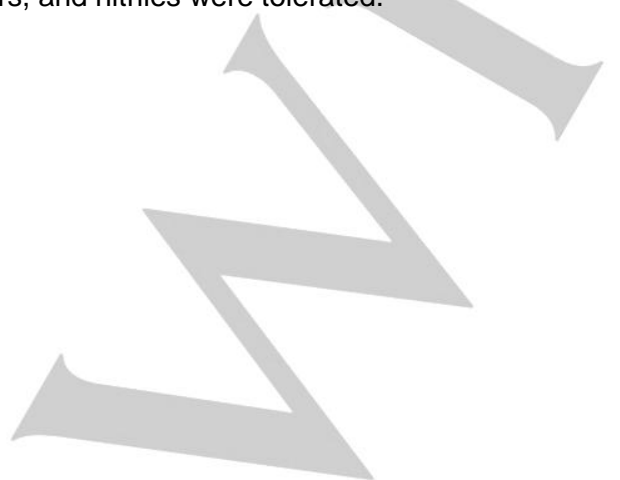

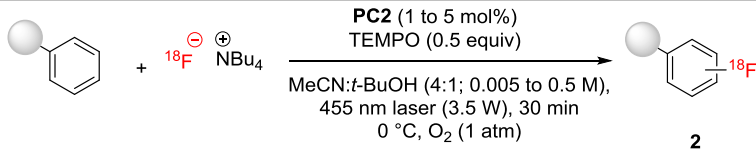

Selected examples<smiles>Fc1ccc(P)cc1</smiles><smiles>COc1ccc(F)cc1Br</smiles><smiles>COc1ccc(F)cc1Cl</smiles>

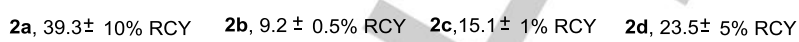

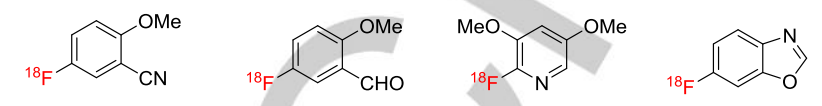
2e, $11.1 \pm 2 \% \mathrm{RCY} \quad 2 \mathrm{2f}, 23.5 \pm 4 \% \mathrm{RCY} \quad \mathbf{2 g}, 11.1 \pm 2 \% \mathrm{RCY} \quad \mathbf{2 h}, 7.1 \pm 0.5 \% \mathrm{RCY}$

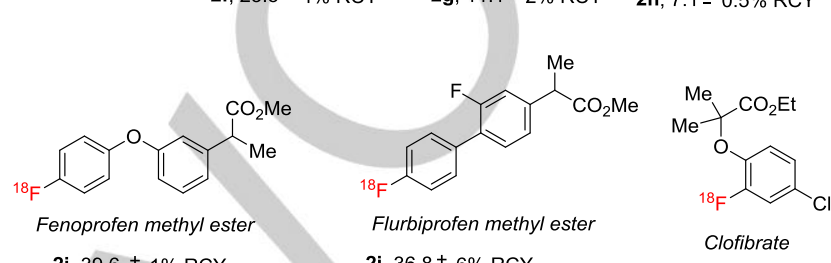

$2 \mathbf{i}, 39.6 \pm 1 \% \mathrm{RCY}$

2j, $36.8 \pm 6 \%$ RCY

2k. $3.7+0.3 \%$ RCY

Scheme 5. Reaction scope of ${ }^{18} \mathrm{~F}$-fluorination of aromatics. RCY stands for radiochemical yields.

A new generation of acridinium photocatalysts was developed in 2017 by Nicewicz, and PC3 demonstrated efficiency in the $\mathrm{C}-\mathrm{H}$ amination with primary amines. ${ }^{[25]}$ In fact, in contrast to previous examples where prefunctionalized chloroamines are combined with arenes under strong Bronsted acidic conditions ${ }^{[26]}$, it was shown that the reaction of arenes with a wide variety of amino ester hydrochloride salts in a mixture of 1,2-dichloroethane and at $\mathrm{pH} 8$ afforded the expected aminated arenes. Remarkably, the ortho isomer was observed as the major adduct when anisole was used as the arene. However, the para regioisomer could be favoured by using tert-butyldimethylsilyl (TBS) phenyl ether as the arene coupling partner. The protocol tolerates various functionalities and some amination products were observed as single diastereomers. This clearly indicates the resistance of those amino acids against epimerisation during the reaction (Scheme 6). 


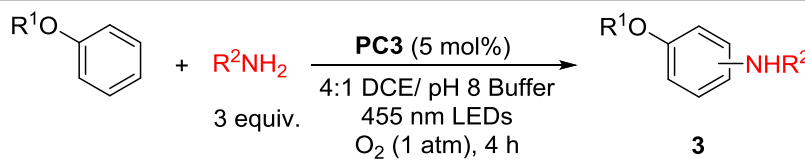

Selected examples

$\mathrm{R}^{1} \mathrm{O}$<smiles>[R]C(Nc1ccc(C)cc1)C(C)=O</smiles>

3a, $\mathrm{R}^{1}=\mathrm{TBS}, \mathrm{R}_{2}=\mathrm{H}, 49 \% ; 1: 1.8$ o:p

3b, $\mathrm{R}^{1}=\mathrm{Me}, \mathrm{R}_{2}=\mathrm{Me}, 62 \% ; 1.2: 1.8$ o:p $3 \mathrm{~d}, \mathrm{R}^{1}=\mathrm{Me}, 77 \% ; 1.5: 1$ o:p

3c, $\mathrm{R}^{1}=\mathrm{Me}, \mathrm{R}_{2}=i \mathrm{Pr}, 80 \% ; 2.2: 1$ o:p $\quad 3 e, \mathrm{R}^{1}=\mathrm{TBS}, 85 \% ; 1: 1.4$ o:p<smiles>[R][Y]1ccc([R20])cc1</smiles>
$\mathrm{R}^{1} \mathrm{O}$

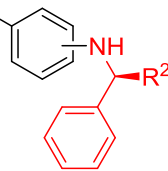

3f, $\mathrm{R}^{1}=\mathrm{Me}, \mathrm{R}^{2}=i \mathrm{Pr}, 53 \% ; 1.2: 10: p$

3g, $\mathrm{R}^{1}=\mathrm{TBS}, \mathrm{R}^{2}=n \mathrm{Pr}, 61 \% ; 1: 1.8$ o:p

3h, $\mathrm{R}^{1}=\mathrm{TBS}, \mathrm{R}^{2}=$ allyl, $80 \% ; 1: 2.20: p$

3i, $\mathrm{R}^{1}=\mathrm{Me}, \mathrm{R}^{2}=\mathrm{Me}, 74 \% ; 1.4: 1$ o:p 3j, $\mathrm{R}^{1}=\mathrm{TBS}, \mathrm{R}^{2}=\mathrm{H}, 70 \% ; 1: 1.8$ o:p<smiles>COc1ccccc1NC(C)C12CC3CC(CC(C3)C1)C2</smiles><smiles>COc1ccccc1NC(C)COc1c(C)cccc1C</smiles><smiles>CCC1(CNc2ccc(OC)cc2OC)CCCCC1</smiles>

$3 \mathrm{~m}, 34 \% ; 1.2: 10: p$

$3 k, 45 \%$

3I, $41 \%$

the group of Nicewicz.

Scheme 6. Direct aryl C-H amination developed by the group of Nicewicz.

In contrast to the previous mechanisms discussed above, where the generation of an arene radical cation was postulated, the authors suggested the formation of amine radical cation through the oxidation of the amine by the excited state of the photocatalyst. The addition of the arene to the radical cation forms the cycohexadienyl radical that can be rearomatized by molecular oxygen. However, the generation of an arene radical cation could not be completely ruled out especially for amines and arenes possessing similar oxidation potentials.

Taking advantage of the ability of PC2 to generate arene radical cations under mild conditions, the Nicewicz group employed $\mathrm{Me}_{3} \mathrm{SiCN}$ as a cyanide nucleophile for the synthesis of aromatic nitriles via direct $\mathrm{C}-\mathrm{H}$ functionalization. ${ }^{[27]}$ The reaction proceeds under aerobic atmosphere and basic media $(\mathrm{pH}=9)$ and was found to be compatible with a large variety of functionalities, including, halogens, oxygen- and nitrogen- containing heterocycles (Scheme 7). It was shown that monosubstituted aromatics undergo $\mathrm{C}-\mathrm{H}$ bond functionalization at the paraposition. The regioselectivity was explained by the location of partial charges on the arene radical cations (vide infra).

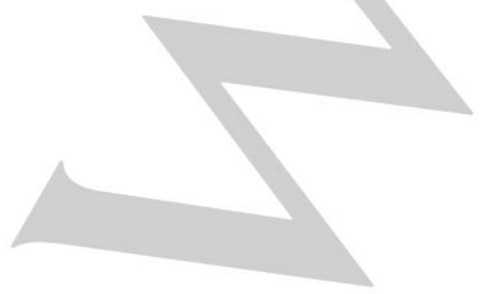




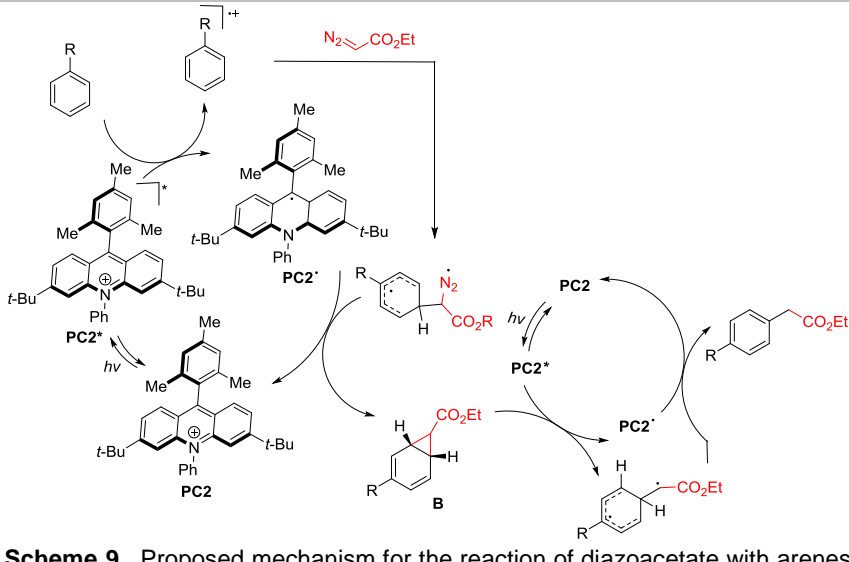

Scheme 9. Proposed mechanism for the reaction of diazoacetate with arenes developed by the group of Nicewicz

\subsubsection{Oxidation of alkoxyarenes}

Nucleophilic aromatic substitution is arguably one of the most important organic transformations as it allows the formation of carbon-carbon and carbon-heteroatom bonds on an aromatic ring. ${ }^{[29]}$ Based on the ability of acridinium ions to oxidize methoxyarenes (vide infra), the same group hypothesized that with the absence of a terminal oxidant, the ipso $\sigma$-complex could undergo rearomatization to give an overall inverse electrondemand $S_{N} A r$ affording the final adduct (Scheme 10).

$$
\text { OMe }
$$

Scheme 10. $S_{N} A r$ reaction via the formation of radical cation.

By employing PC2 as a photocatalyst, a range of methoxyarenes and benzyloxyarenes reacted with imidazole to give the corresponding $N$-arylimidazoles. The reactions were performed in a mixture of DCE:TFE $(1: 1)$ at $33{ }^{\circ} \mathrm{C}$ under blue LEDs irradiation. ${ }^{\left[{ }^{30}\right]}$ It should be mentioned that the reaction could also be extended to the synthesis of aniline $\mathbf{6 k}$ by using a large excess of ammonium carbamate ( 8 equiv.) as well as trifluoroethylarylether $6 \mathrm{I}$ with trifluroethanol in moderate yields. Importantly, brominated and fluorinated anisoles were tolerated and the protocol was successfully applied for late-stage functionalization of complex molecules (Scheme 11).

1 equiv. $1.1-4$ equiv. $\underset{\substack{1: 1 \mathrm{DCE} / \mathrm{TFE} \\ 455 \mathrm{~nm} \text { LEDs } \\ 33^{\circ} \mathrm{C}, \mathrm{N}_{2}}}{\mathrm{PC2}(5 \mathrm{~mol} \%)}$

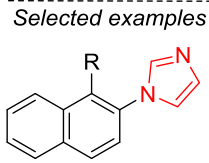

6a, $\mathrm{R}=\mathrm{Cl}, 52 \%$

6b, $\mathrm{R}=\mathrm{CN}, 99 \%$

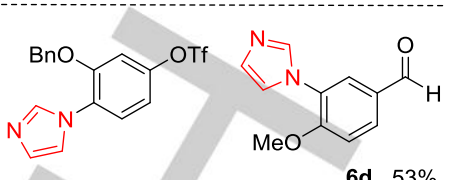

$6 c, 76 \%$

6 d, $53 \%$<smiles>[R]c1ccc(-n2ccnc2)c([R])c1</smiles>

6e, $\mathrm{R}^{1}=\mathrm{Cl}, \mathrm{R}^{2}=\mathrm{Cl}, 79 \%$ 6f, $\mathrm{R}^{1}=\mathrm{Br}, \mathrm{R}^{2}=\mathrm{Cl}, 78 \%$<smiles></smiles>

6g, $99 \%$

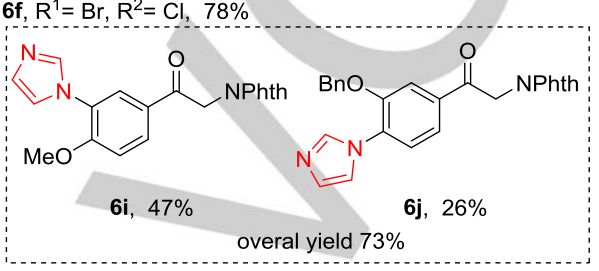

Scheme 11. Nucleophilic aromatic substitution with imidazole developed by the group of Nicewicz. Tf: triflate, NPhth: Phthalimide, Piv: pivaloyl.

An elegant sequential $\mathrm{C}-\mathrm{H}$ functionalization and $\mathrm{S}_{\mathrm{N}} \mathrm{Ar}$ reactions was achieved using naproxen methyl ester to afford the desired product 7 (Scheme 12).

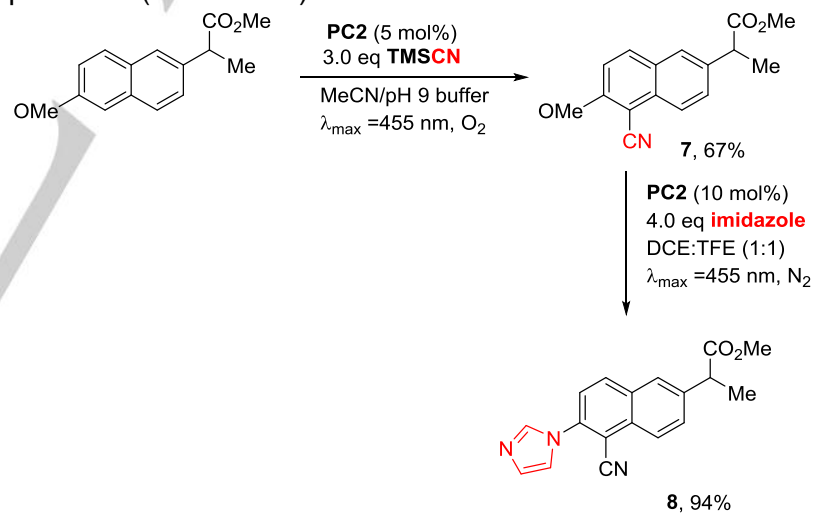

Scheme 12. Sequential $\mathrm{C}-\mathrm{H}$ functionalizaiton/Nucleophilic aromatic substitution developed by the group of Nicewicz.

Afterwards, Nicewicz et al. employed the cation radicalaccelerated nucleophilic aromatic substitution (CRA-S $\mathrm{S}_{N} \mathrm{Ar}$ ) of alkoxyarenes with the commercially available acetone cyanohydrin in the presence of PC2 as a photocatalyst for the synthesis of aryl nitriles. The reactions were performed DCE:TFE (3:1) in the presence of $\mathrm{NaHCO}_{3}$ as base (5 equiv.). ${ }^{[31]}$ In contrast with the well-known Sandmeyer reaction, this approach proceeds under mild conditions and tolerates various functional groups. Arenes bearing 1,2-dimethoxy substituents and 1,2-dimethoxybenzophenones performed well with yields ranging from moderate to excellent (Scheme 13). The approach was also compatible with complex substrates such as the letrozole $\mathbf{8} \mathbf{i}$ and noradrenaline derivatives $\mathbf{9 k}$ and $\mathbf{9} \mathbf{k}^{\mathbf{\prime}}$ albeit in low to moderate yields. Based on natural population analysis 
(NPA) the authors showed that the regioselectivity of the ipsofunctionalization could be predicted and are in good agreement with the observed results.

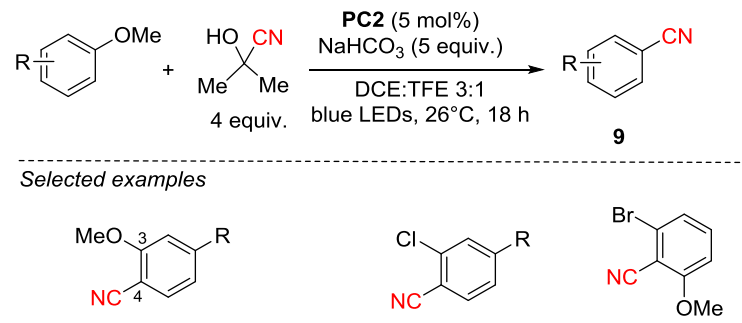

9a, $\mathrm{R}=\mathrm{CN}, 90 \%(2.4: 1 \mathrm{C} 4: \mathrm{C} 3)$

9d, $\mathrm{R}=\mathrm{Cl}, 77 \%$ 9b, $\mathrm{R}=\mathrm{CO}_{2} \mathrm{Me}, 70 \%(1.9: 1 \mathrm{C} 4: \mathrm{C} 3) \quad \mathbf{9 e}, \mathrm{R}=\mathrm{Ph}, 39 \%$ 9c, $\mathrm{R}=\mathrm{CF}_{3}, 49 \%(1: 2.3 \mathrm{C} 4: \mathrm{C} 3) \quad$ 9f, $\mathrm{R}=t \mathrm{Bu}, 54 \%$ 9g, $54 \%$<smiles>COC(=O)CCC(=O)c1ccc(C#N)c(OC)c1</smiles><smiles>COc1ccc(C(c2ccc(C#N)cc2)n2cncn2)cc1</smiles>

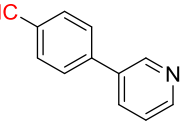

$$
\text { 9h, 51\% (1.6:1 C4:C3) }
$$

9i, $16 \%$ 9j, $20 \%$

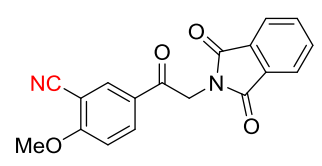

9k'

$9 k$

9k:9k' (1:1.6) $47 \%$ overall yield

Scheme 13. Cyanation of arenes through nucleophilic aromatic substitution developed by the group of Nicewicz.

Further expansion of photocatalyzed CRA-S $\mathrm{S}_{\mathrm{N}} \mathrm{Ar}$ of anisoles has been reported by the Nicewicz group and focuses on the amination with primary amines. ${ }^{\left[{ }^{32]}\right.}$ In this context, PC2 have shown efficiency for the reactions of mono-, di-, and trimethoxy arenes, accessible from lignin derived feedstock chemicals reacted with primary amines and the resulting aniline products have been isolated in good yields (Scheme 14). The reactions were performed in DCE at $33^{\circ} \mathrm{C}$ under blue LEDs irradiation. This transformation is complementary to traditional $S_{N} A r$ and transition metal cross-coupling reactions.
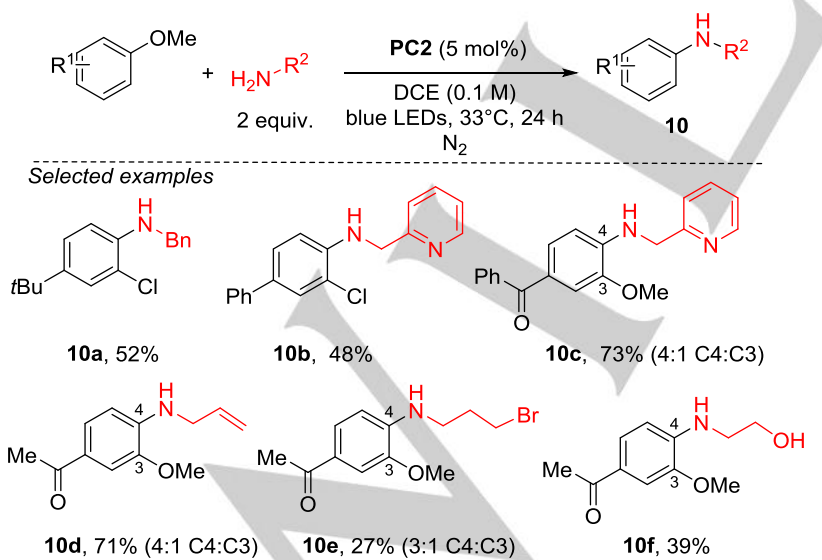

10d, $71 \%(4: 1 \mathrm{C} 4: \mathrm{C} 3) \quad 10 \mathrm{e}, 27 \%(3: 1 \mathrm{C} 4: \mathrm{C} 3)$

nucleophilic aromatic substitution developed by the group of Nicewicz.

Inspired by this study, Lawson, Murphy and co-workers have recently demonstrated that PC2 could catalyse Smiles rearrangements and annulations of non-activated aromatics (Scheme 15). ${ }^{[33]}$ The reactions were performed either in TFE or in a mixture of TFE:TFT (1:1) under blue LEDs irradiation at

$29^{\circ} \mathrm{C}$. In this regard, various primary aryloxyamines have been oxidized to the corresponding radical cations. The tethered primary amine adds to the ipso-position, giving rise to Meisenheimer complex, which lead to the Similes rearrangement adduct after proton transfer and reduction by the acridinyl radical (Scheme 16).

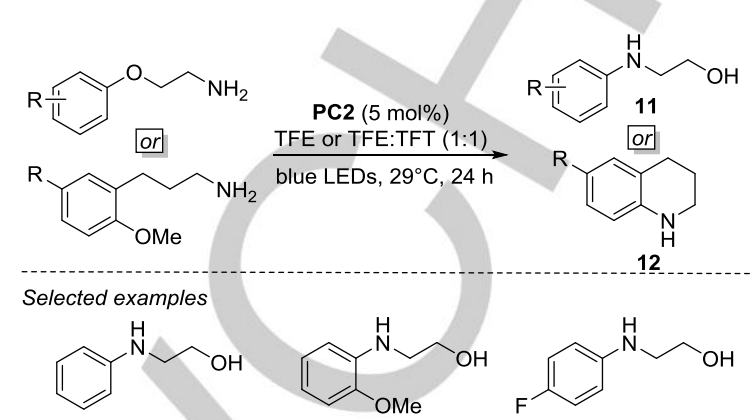

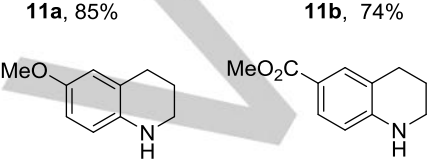

12a, $49 \%$

12b, $38 \%$

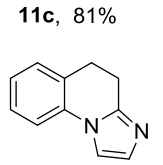

12c, $80 \%$
Scheme 15. Smiles rearrangements and annulations developed by the group of Lawson and Murphy. 
visible light approach will undoubtedly be further developed and applied (Scheme 17).

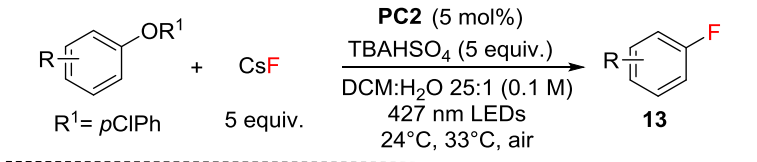

$$
\text { Selected examples }
$$

13a, $\mathrm{R}=p \mathrm{Ph}, 79 \%$ 13b, R=oPh, $76 \%$ 13c, R= pOPiv, $68 \%$ 13d, $\mathrm{R}=p \mathrm{Cl}, 60 \%$<smiles>COC(=O)[C@H](Cc1ccc(F)cc1)Nc1ccccc1</smiles>

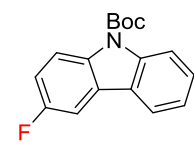
$13 \mathbf{i}, 37 \%$

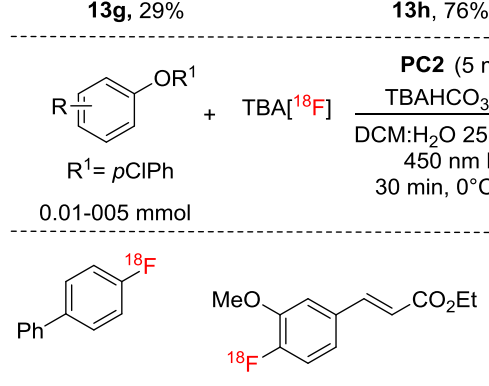

$14 a, 94,6 \pm 0.4 \%$

$$
\text { 14b, } 54,4 \pm 7 \%
$$

13 e, $42 \%$<smiles>Fc1ccc(-c2cccnc2)cc1</smiles>

13f, $60 \%$<smiles>COc1cc2c(cc1F)[C@@H]1CC[C@]3(C)[C@@H](OC)CC[C@@H]3[C@@H]1CC2</smiles>
$14 \mathrm{e}, 12.2 \pm 1 \%$

$14 d, 85.0 \pm 2 \%$<smiles>COc1cc(CC(NC(C)(C)C)C(C)=O)ccc1F</smiles>

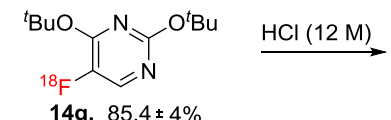

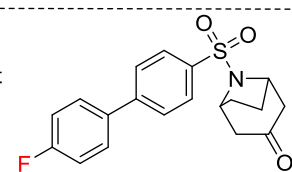

14c, $64.2 \pm 3 \%$ by the groups of Nicewicz and Li (low numbers correspond to radiochemical yields). Boc: tert-butoxycarbonyle.

\subsubsection{Dual catalysis Acridinium/iminium for the enantioselective} $\beta$-functionnalisation of enals

Very recently, the group of Melchiorre has shown that PC2 can be combined with a chiral secondary amine to catalyze the enantioselective conjugate addition of carbon-centered radicals to aliphatic and aromatic enals (Scheme 18$).{ }^{[35]}$ The reactions were performed in MeCN under blue LED irradiation in the presence of TFA ( 0.6 equiv.) at $-10{ }^{\circ} \mathrm{C}$. The reaction exhibits a large substrate scope, including various carbon radical precursors and enals (both aliphatic and aromatic). Importantly, both primary and secondary radicals can be added with high stereocontrol. This approach opens new avenues for the enantioselective addition of other radicals under metal-free conditions.
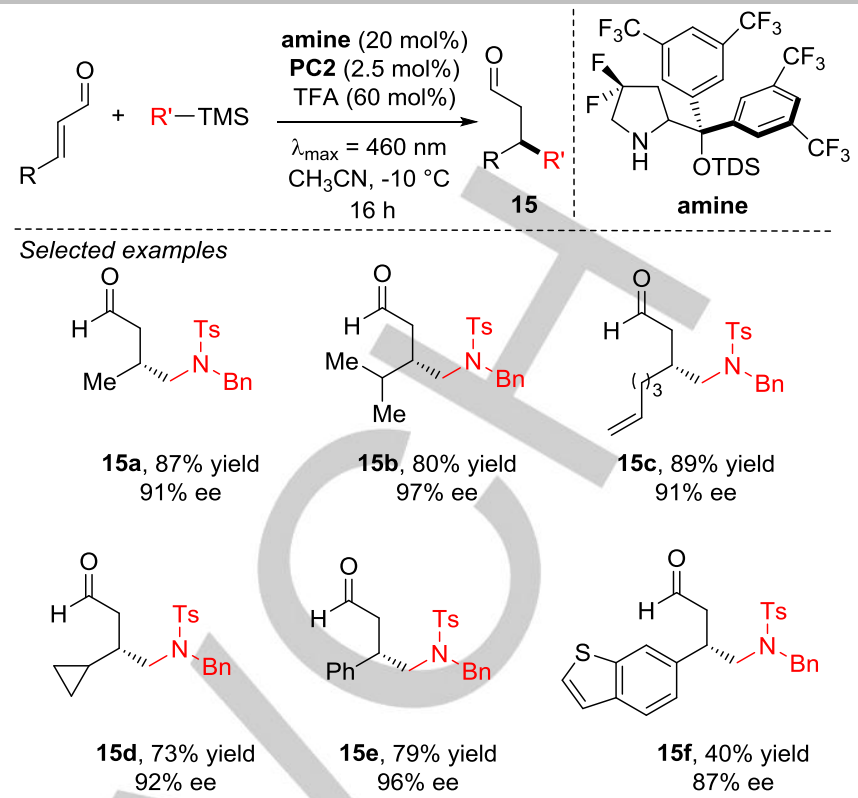
$16 \mathrm{~h}$ 15 $92 \%$ ee $96 \%$ ee

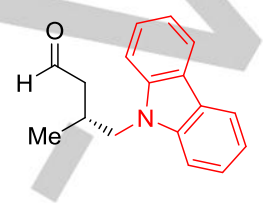

$15 \mathrm{~g}, 62 \%$ yield $62 \%$ ee<smiles>O=CC[C@@H](CO)CSc1ccccc1</smiles>

$15 \mathrm{~h}, 62 \%$ yield $96 \%$ ee
Scheme 18. Enantioselective conjugate addition of carbon-centered radicals to aliphatic and aromatic enals developed by the group of Melchiorre. TMS: trimethylsilyl, Tosyl: Ts.

From a mechanistic standpoint, while the secondary amine catalyst reacts with enal to form the corresponding $\alpha, \beta$ unsaturated iminium ion, ${ }^{[36]}$ the photocatalyst oxidizes the alkyl silane generating a carbon radical that can subsequently react with the iminium ion $\mathbf{C}$ to form a new radical intermediate $\mathbf{D}$. The latter is reduced to form the enamine intermediate $\mathbf{E}$ and the photocatalyst is released. Finally, a hydrolysis delivers the desired product (Scheme 19). 


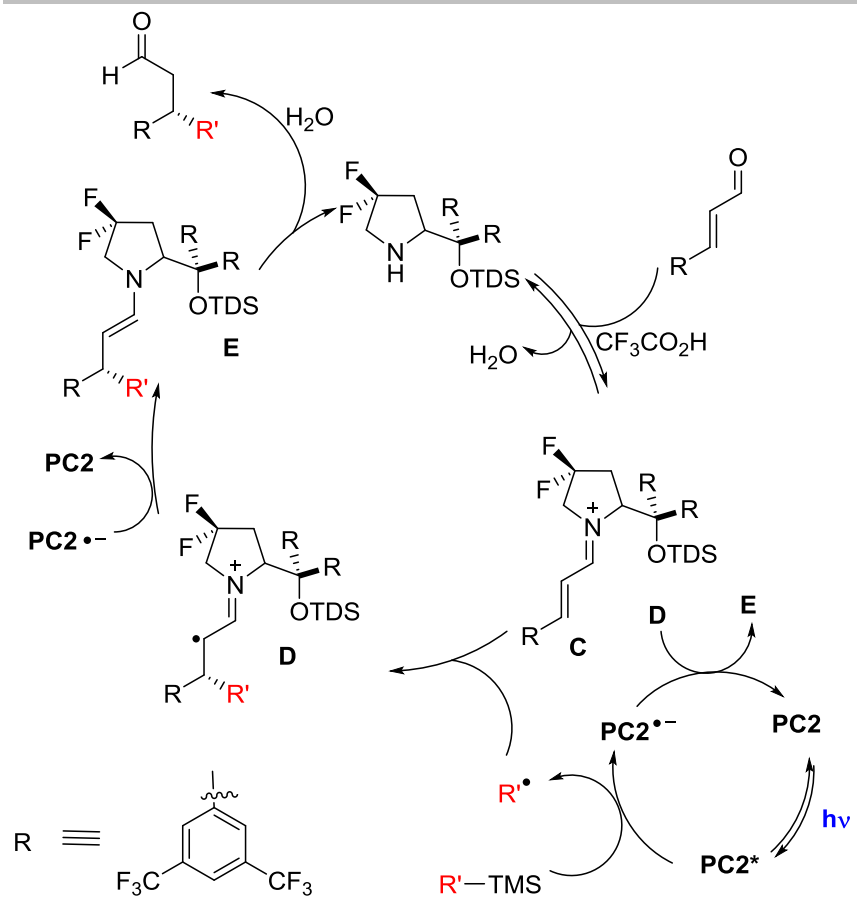

Scheme 19. Proposed mechanism for the enantioselective conjugate addition of carbon-cantered radicals to aliphatic and aromatic enals. developed by the group of Melchiorre

\subsubsection{Reductive dehalogenation and detosylation}

Recently, Nicewicz et al. demonstrated through detailed spectroscopic and DFT studies the super reducing ability of the acridine radical, formed upon single electron reduction of PC2. Indeed, with a maximum excited state volts vs SCE, the acridine radical photoreactivity is comparable of that of elemental lithium (Scheme 20). ${ }^{[37]}$ This reactivity is unique and highly interesting as the lifetimes of doublet excited states of neutral organic radicals are typically several orders of magnitude shorter than the singlet lifetimes of common transition-metal photoredox catalysts.

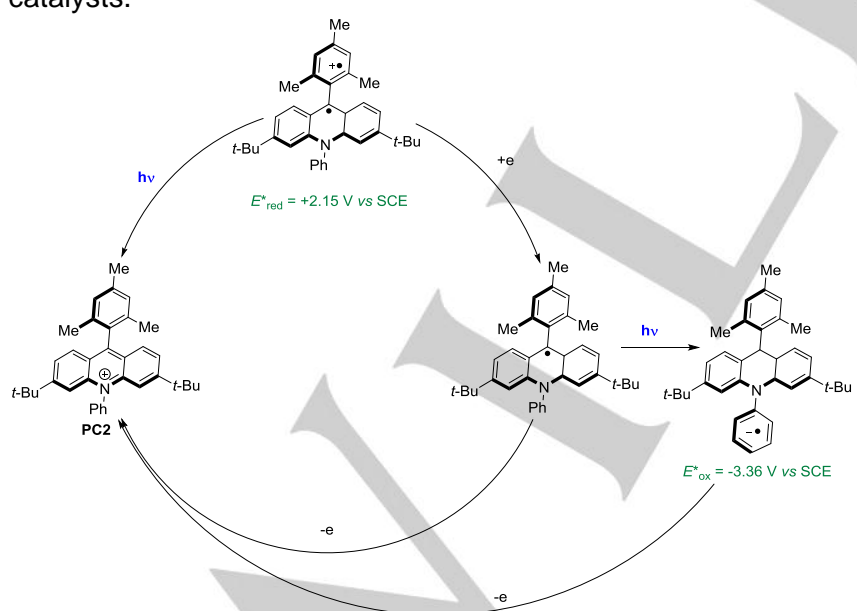

Scheme 20. Investigation of the super reducing ability of the acridine radical

The reactivity of the acridine radical as super photoreductant has been highlighted in dehalogenation and desulfonylation reactions. By using diisopropylamine ( ${ }^{i} \mathrm{Pr}_{2} \mathrm{NEt}$ ) as single electron reductant, the excited state of $(\mathbf{P C 2})^{*}$ is quenched to form the ground state $\mathbf{P C 2}^{-}$that forms the acridine radical upon excitation with a second photon. The later is able to reduce a large variety of aryl halides to form the corresponding aryl radicals, which undergo hydrogen atom transfer from amine radical cations to form the desired product. Importantly, the protocol is high yielding and also tolerates many functionalities (ketone, carboxylic acid, alcohol...) (Scheme 19). The same approach works equally well in reductive detosylation of amines, which is traditionally performed under strong acidic conditions or in the presence of dissolving metal $(\mathrm{Li} / \mathrm{Mg})$ (Scheme 21).
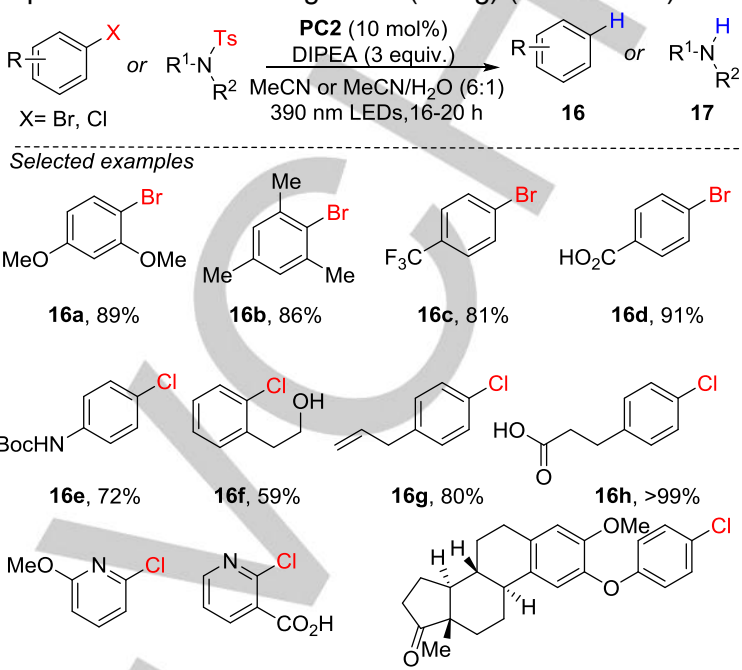

$$
16 \mathbf{i}, 75 \% \quad 16 \mathbf{j}, 87 \% \quad 16 \mathrm{k}, 58 \%
$$

Selected examples
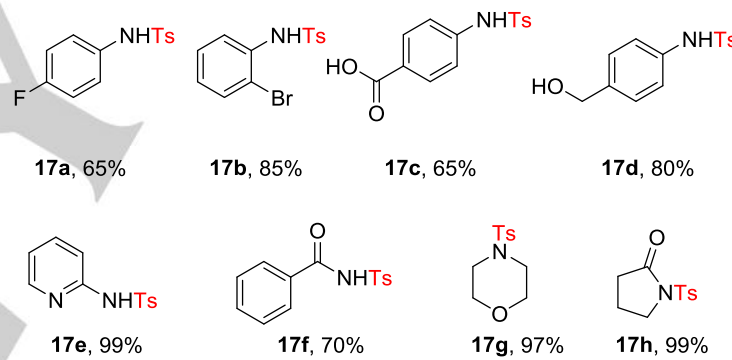

Scheme 21. Reductive dehalogenation of aryl halides and reductive detosylation developed by the group of Nicewicz.

\subsection{Emerging Acridinium Photocatalysts}

In order to access a large variety of acridinium salts with modified photophysical and electrochemical properties, new synthetic routes have recently emerged. For instance, Mancheño and Alemán reported an oxidative Ugi-type reaction for the synthesis of imideacridinium salts. ${ }^{[38]}$ The latter have shown promising photocatalytic activities in benchmark reactions such as oxidation of alcohol, anti-Markovnikov hydrofunctionalization of alkenes and a dehydrogenative lactonization (Scheme 22). 
WILEY-VCH

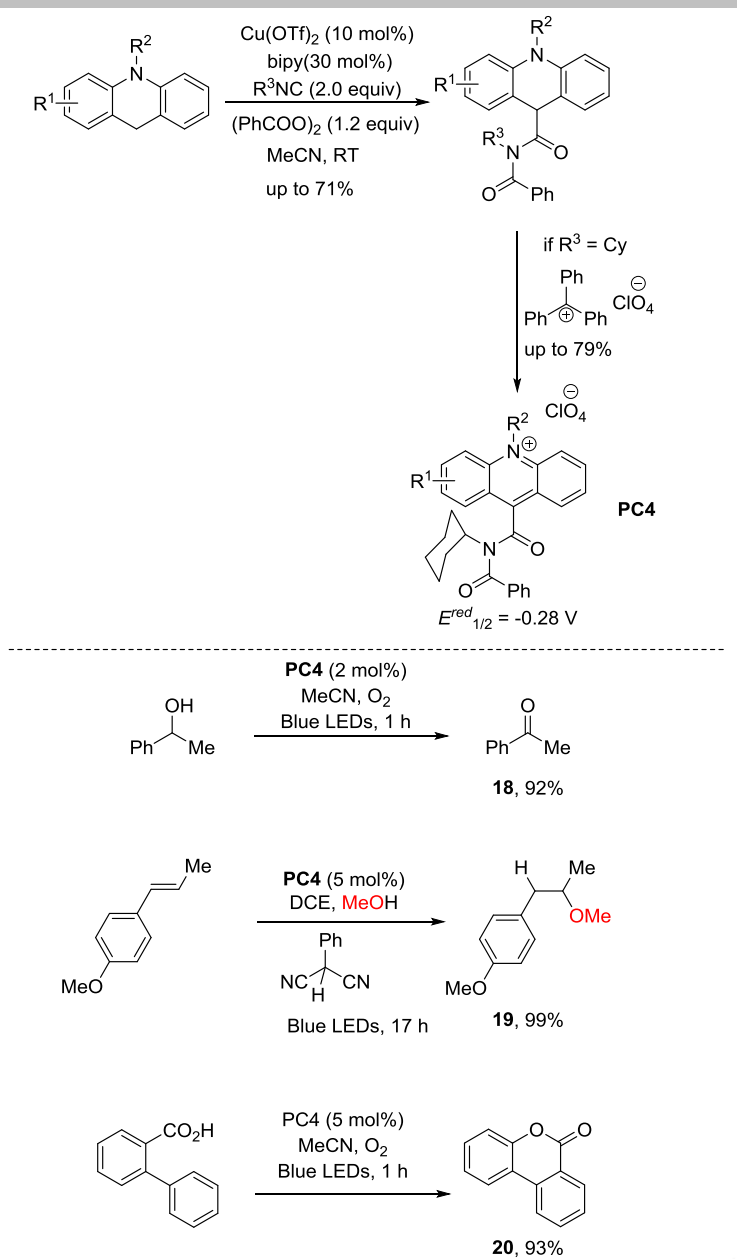

Scheme 22. New acridinium based photocatalyst developed by Mancheño and Alemán

Interestingly, the Sparr's group developed three complementary synthetic strategies enabling a rapid access to a large variety of acridinium salts with structural variations at the nitrogen as well as the aromatic positions of the acridine. ${ }^{[8]}$ As depicted in Scheme 22, the first approach relies on the combination of 1,5bufinctionnal organometallic reagents with esters to allow access to acridinium salts bearing different aryl groups at C9 position. Access to 1,8-dimethoxy substituted acridinium dyes was accomplished through a double directed ortho-methalation approach to generate the 1,5-organolithium reagent that intercept with various esters (Scheme 23). Finally, the combination of directed ortho-metalation (DoM) and halogen metal exchange $(\mathrm{X}-\mathrm{M})$ processes enabled the synthesis of a wide range of asymmetric acridinium salts in good to excellent yields (Scheme 24). ${ }^{[39]}$
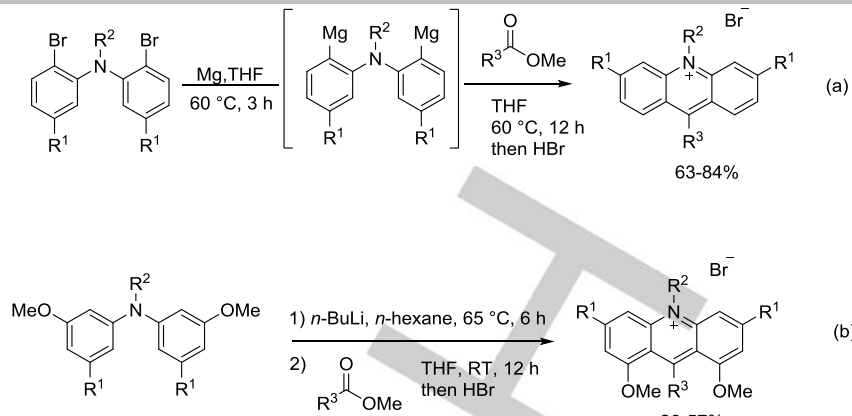
$26-57 \%$

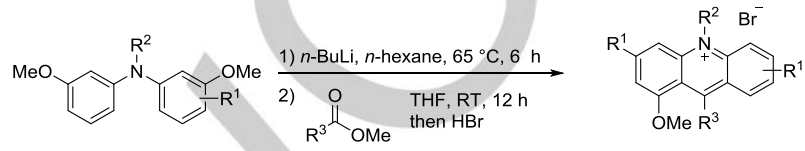

Scheme 23. Sparr's approaches for synthesis of acridiniums salts.

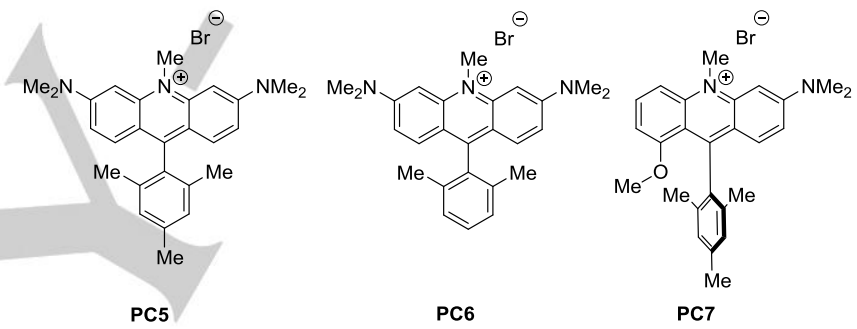

$\lambda_{\text {asm } \max }=503 \mathrm{~nm}$ $\lambda_{\text {em, } \max }=534 \mathrm{~nm}$ $E_{1 / 2}\left(\mathrm{PC}^{\star} / \mathrm{PC}^{-}\right)=1.25 \mathrm{~V}$ $\tau=2.20 \mathrm{~ns}$
$P C 6$

$\lambda_{\text {abs,max }}=504 \mathrm{~nm}$ $\lambda_{\mathrm{em}, \max }=533 \mathrm{~nm}$ $E_{1 / 2}\left(\mathrm{PC}^{*} / \mathrm{PC}^{-}\right)=1.2 \mathrm{~V}$ $\tau=-$
$\mathrm{PC7}$

$\lambda_{\text {abs, } \max }=513 \mathrm{~nm}$ $\lambda_{\text {em, } \max }=573 \mathrm{~nm}$ $E_{1 / 2}\left(\mathrm{PC}^{*} / \mathrm{PC}^{-}\right)=+1.24 \mathrm{~V}$ $\tau=1.1,6.8 \mathrm{~ns}$
Scheme 24. Photophysical and electrochemical properties of new acridinium photocatalysts

By using these different synthetic approaches, a library of new acridinium salts is now accessible and the photophysical and electrochemical properties of these photocatalyst were studied by the groups of Sparr and Wenger. Importantly, photocatalysts (PC5 to 7) depicted in Scheme 24, were tested in a few benchmark reactions including $\mathrm{C} s p^{2}-\mathrm{C} s p^{3}$ bond formation process, decarboxylative fluorination, deuteration, hydroarylation and showed interesting activities (Scheme 25). Remarkably, these new photocatalysts are competitive with, and some time even better than common organometallic and organic dyes, which reflects their high synthetic potential. 

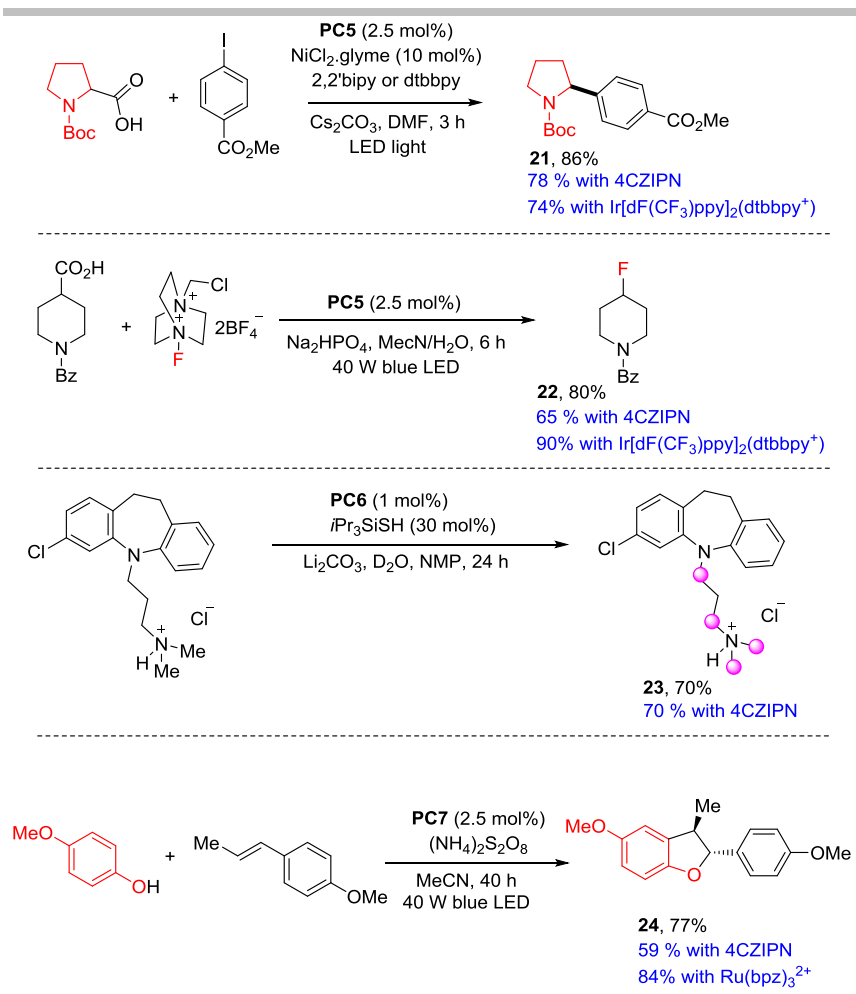

Scheme 25. Selected application of the new acridinium photocatalysts developed by the group of Sparr. Bz: benzoyl.

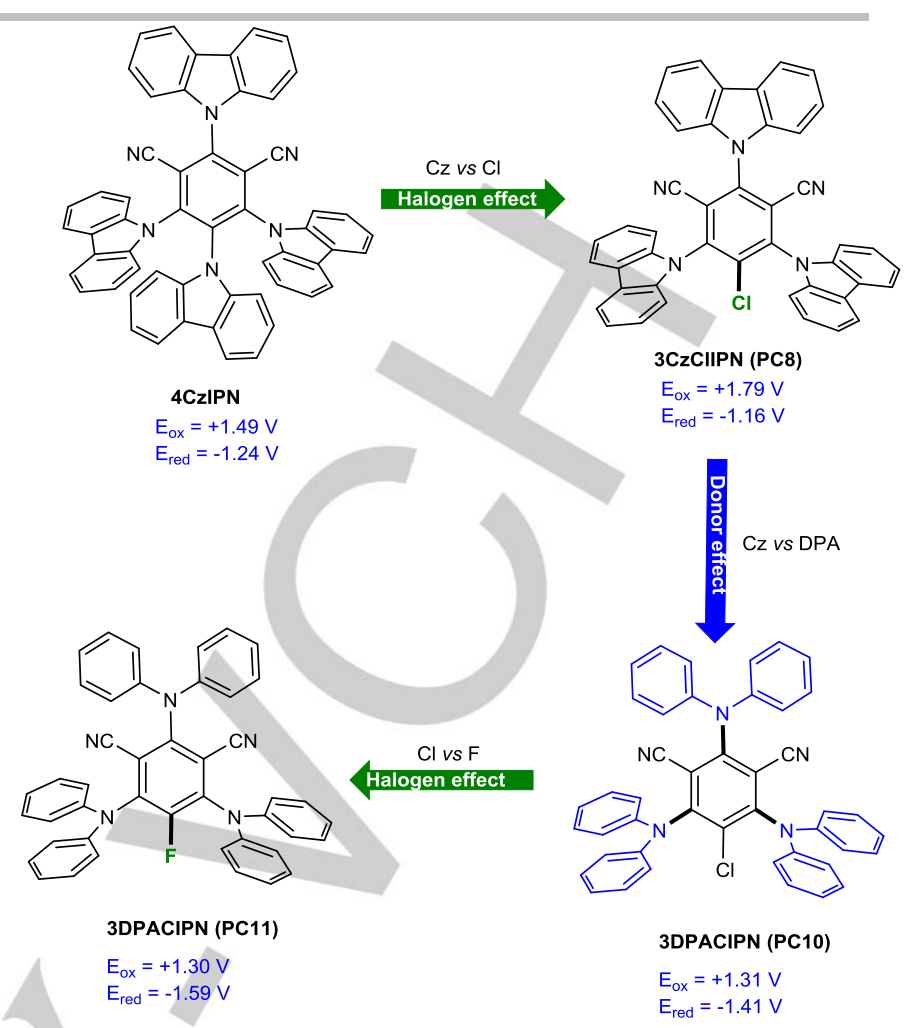

Scheme 26. Impact of the substituents on cyanoarenes photocatalyst

\section{Cyanoarene-based organophotocatalysts}

Cyanoarenes are very attractive organophotocatalysts that have shown very interesting reactivity in photoredox catalysis. ${ }^{[10]}$ This is mainly due to the electrochemical properties of their excited states which range from -0.7 to $-1.7 \mathrm{~V}$ for the reduction potentials and are $+2.0 \mathrm{~V}$ and greater for the reduction potentials. $^{[8]}$

Recently, 1,2,3,5-tetrakis(carbazole-9-yl)-4,6-dicyanobenzene (4CzIPN, PC9) has emerged as one of the most useful catalysts in the series which apart from its reduction potential, exhibits a longer excited state lifetime due to the presence of the carbazole groups. Such structure mimics those found in transition metal photocatalysts, where photoexcitation leads to the transfer of an electron from the HOMO of the metal atom to the LUMO of the ligands. ${ }^{[40]}$

In order to design new effective cyanoarene-based photocatalysts, the group of Zeitler investigated the effects of aromatic, and halogen substitutions on the active core of three newly synthesized, and 5 previously studied cyanoarenes. ${ }^{[40]}$ Remarkably, the substitution of one of the carbazole moieties of (4CzIPN, PC9) by a chlorine increases the reduction potential of PC8 of $0.3 \mathrm{~V}$ (Scheme 25). Moreover, the donor effect has also been investigated and it was shown that the replacement of the carbazole moiety by a diphenylamine leads to increasing the reduction potential by $0.25 \mathrm{~V}$ (PC 10). Finally, changing the chlorine of the latter by a fluorine enhances further the reduction ability (PC11) (Scheme 26). Table 1 shows both the oxidation and reduction potentials of selected cyanorarenes.
Table 1. Redox potentials of selected cyanoarene PC photocatalysts.

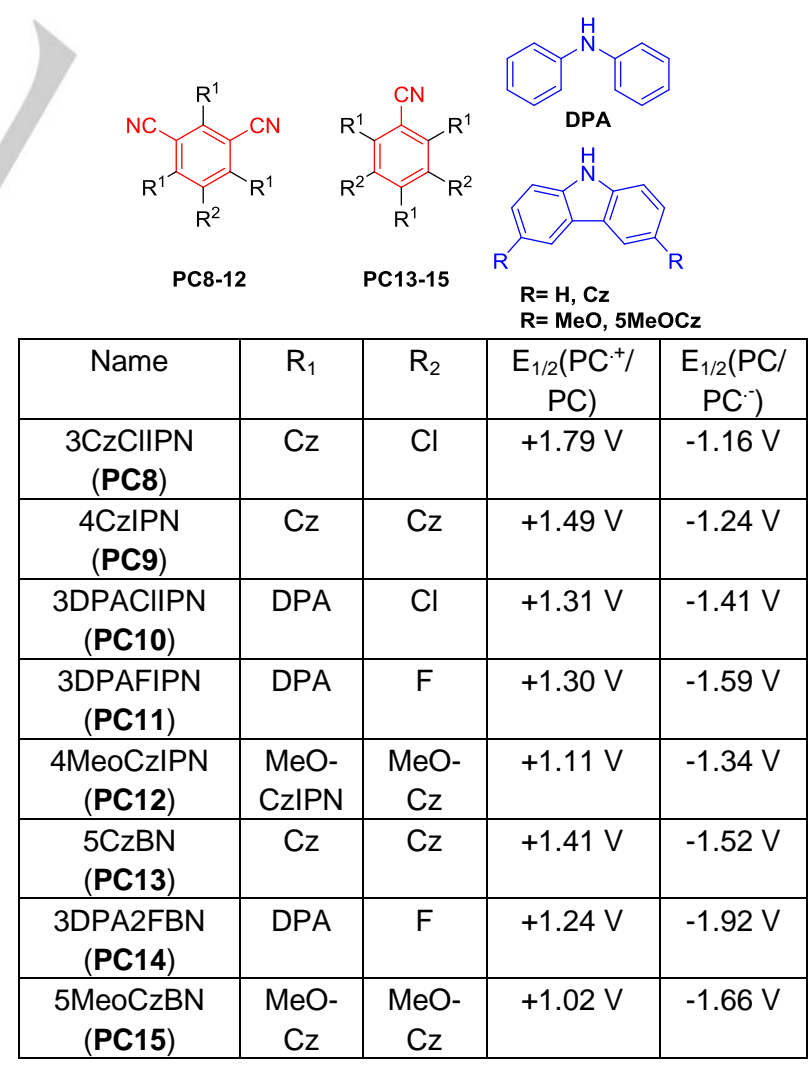


WILEY-VCH

\subsection{Selected recent examples of photoredox catalysis with} cyanoarene photocatalysts

\subsubsection{Carboxylations:}

The challenging metal free direct carboxylation of benzylic $\mathrm{C}-\mathrm{H}$ bonds was developed by the group of Konig. ${ }^{[41]}$ The reactions were performed in DMF under 4 atm of $\mathrm{CO}_{2}$ at $0{ }^{\circ} \mathrm{C}$ for $24 \mathrm{~h}$. Herein, PC9 (6 mol\%) was used in conjunction with catalytic amount of triisopropylsilanethiol (20 mol\%) and the developed conditions showed high tolerance toward a variety of starting materials. The desired compounds were obtained with synthetically useful to excellent yields. Interestingly, the authors showed that the conditions could be applied for the straightforward synthesis of drugs including Fenoprofen, Flurbiprofen, Ibuprofen as well as Naproxen in moderate to very good yields. It should be mentioned that other photocatalysts were also used for the reaction scope, PC9, PC11 and PC14. From a mechanistic standpoint, the authors demonstrated that the presence of radical inhibitor is deleterious for the reaction outcome. Also, no H/D scrambling was observed running the reaction in $d_{7}$-DMF. Furthermore, it turns out that the $\mathrm{C}-\mathrm{H}$ bond cleavage is involved in the rate-determining step since a kinetic isotope effect in the intramolecular and intermolecular experiments was observed. Also, the authors detected the formation of a novel reactive photocatalyst during the reaction. Indeed, one cyano group could be substituted by the benzylic radical in the presence of the triisopropylsilanethiol to form 4CzPEBN (PC15, Scheme 26). In light of these observations, the authors proposed the following mechanism, a reductive quenching of the excited $4 \mathrm{Cz} \mathrm{PEBN}^{*}$ by triisopropylsilanethiol is taking place forming the reduced photocatalyst (4CZPEBN ${ }^{-}$) and a thiol radical cation $\mathrm{R}^{-\mathrm{SH}^{+}}{ }^{+}$. Subsequently, a deprotonation forms an electrophilic thiyl radical R-S" which is responsible for the abstraction of a hydrogen from the benzylic position to form a new benzylic radical. The formed reduced photocatalyst $\left(4 \mathrm{CZPEBN}^{-}\right)$reduces the benzylic radical to form a new carbanion that react with $\mathrm{CO}_{2}$ to form after protonation the desired product (Scheme 27).

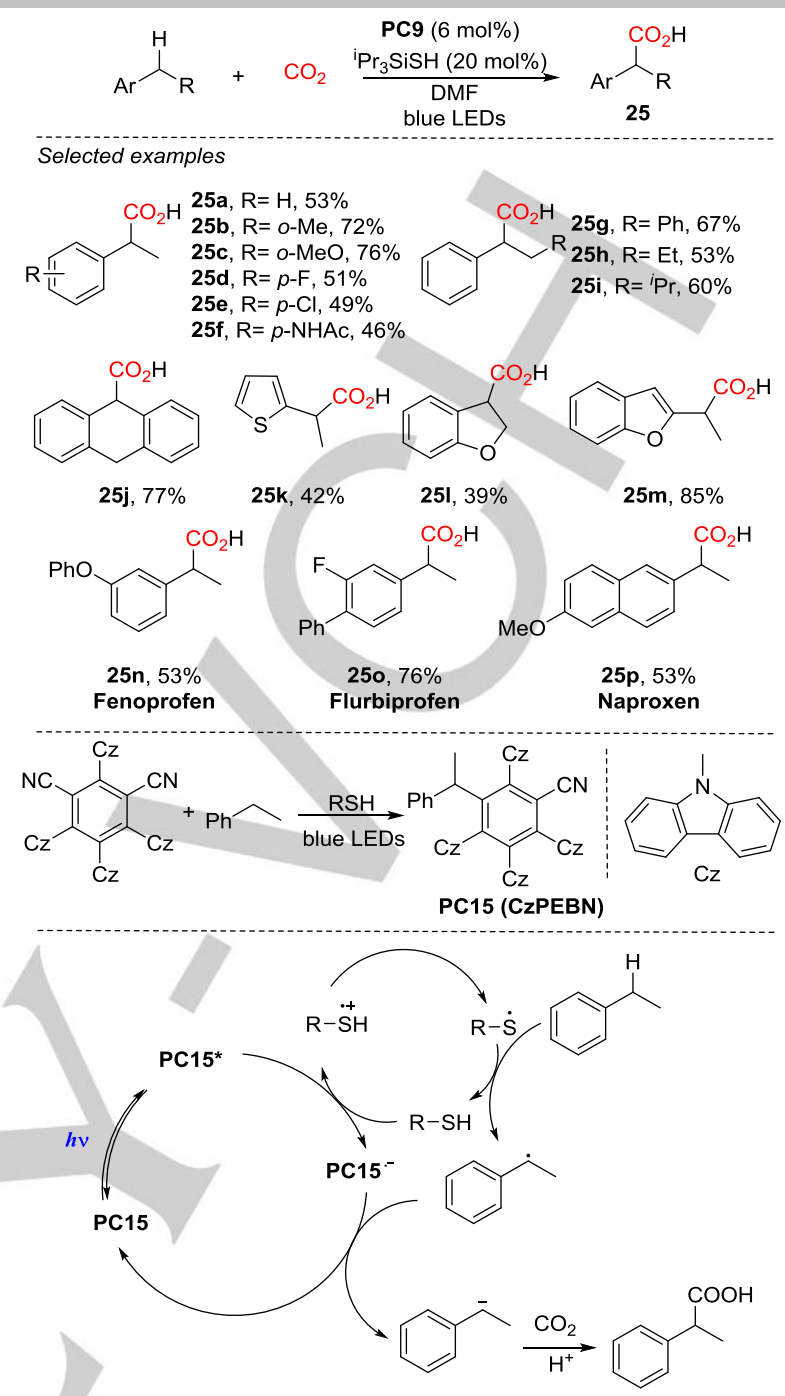

Scheme 27. Phtotocarboxylation of benzylic $\mathrm{C}-\mathrm{H}$ bonds developed by the group of Konig. Ac: Acetyl.

Very recently, the group of Rotstein and Lundgren reported a new methodology for the direct isotopic carboxylate exchange by using cyanoarenes catalyst PC9. ${ }^{[42]}$ It turns out that an alkylative decyanation of PC9 with phenyl acetic acid is taking place insitu yielding a more active catalyst PC16. The authors demonstrated that the exchange process is taking place under atmospheric pressure of ${ }^{13} \mathrm{CO}_{2}$. The labeling of primary, secondary as well as tertiary carboxylic acid derivatives occur under mild reaction conditions. Interestingly, the substrate encompasses a wide variety of complex structure of high interest. More interestingly, the concept was extended to ${ }^{11} \mathrm{C}$ labeling with ${ }^{11} \mathrm{CO}_{2}$ under catalytic conditions of PC16 which actually constitute a breakthrough in radiolabeling applications (Scheme 28). 
WILEY-VCH

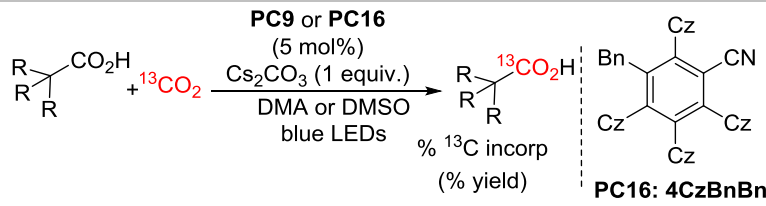

Selected examples

$$
\text { (13) } \mathrm{CO}_{2} \mathrm{H}
$$

26a, R= H, 56\% (50\%) $\mathbf{2 6 b}=p-$ CONEt $_{2}, 60 \%(64 \%)$ c6, $\mathrm{R}=p-\mathrm{MeO}, 32 \%(63 \%)$ 26d, $\mathrm{R}=p-\mathrm{Cl}, 47 \%(70 \%)$ 26e, R= $p$-NHBoc, $66 \%(67 \%$

\section{$\left\langle\mathrm{S} \mathrm{COO}_{2} \mathrm{H}\right.$}

26f, $50 \%(58 \%)$

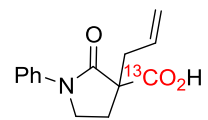

26g, $39 \%(78 \%)$

$$
\overbrace{\mathrm{Ph}}^{13} \mathrm{CO}_{2} \mathrm{H}
$$

26h, $21 \%(72 \%)$<smiles>CC(C(=O)O)c1cccc(Oc2ccccc2)c1</smiles><smiles>COc1ccc2cc(C(C)C(=O)O)ccc2c1</smiles><smiles>Cc1ccc2nc(-c3ccc(O)cc3)c(C[14C](=O)O)n2c1</smiles>

26j, $48 \%(58 \%)$ Fenoprofen

26k, $64 \%(70 \%)$ Naproxen

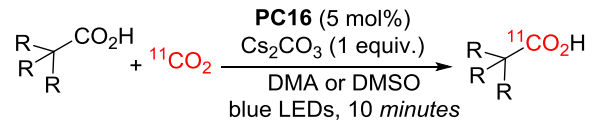

Selected examples

$$
{ }^{\mathrm{NHBz}}
$$<smiles>CC(C(=O)O)c1ccc2c(c1)[nH]c1ccc(Cl)cc12</smiles>

$\mathrm{Me}$

26m, 7\% RCY, $42 \%$ TE 26n, 18\% RCY, $49 \%$ TE $\left[{ }^{11} \mathrm{C}\right]$ Caprofen

RCY: radiochemical yield

TE: rapping efficiency of radioactivity in solution

Scheme 28. Carbon isotope exchange developed by the groups of Rotstein and Lundgren.

A similar strategy for the carbon exchange of benzylic carboxylic acid derivatives. has been developed by the group of Audisio using $\left[{ }^{13} \mathrm{C}\right] \mathrm{CO}_{2}$ and $\left[{ }^{14} \mathrm{C}\right] \mathrm{CO}_{2} \cdot{ }^{[43]}$ Herein $\mathbf{P C 9}$ or PC15 have been used in the presence of $\mathrm{K}_{3} \mathrm{PO}_{4}$ (1 equiv.) in DMF. The desired compounds have been obtained in moderate to excellent yields (Scheme 29). Interestingly, the authors demonstrated high applicability towards pharmaceutically relevant PAA. Moreover, the authors demonstrated that the reactions could be extended also to the Carbon-14 Radiolabeling with $\left[{ }^{14} \mathrm{C}\right] \mathrm{CO}_{2}$. Mechanistically, the oxidation of the carboxylate by PC9* forms the oxygen radical that trigger a decarboxylation to generate a benzylic radical. A subsequent reduction generates the corresponding carbanion that react with $\left[{ }^{13} \mathrm{C}\right] \mathrm{CO}_{2}$ or $\left[{ }^{14} \mathrm{C}\right] \mathrm{CO}_{2}$ to deliver the desired compound (Scheme 30).

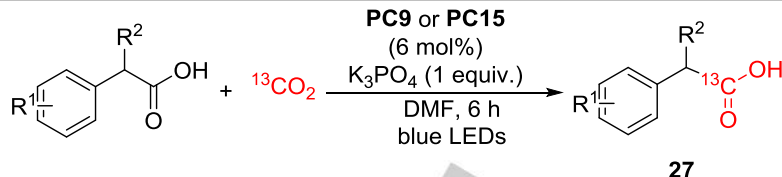

$$
\text { Selected examples }
$$

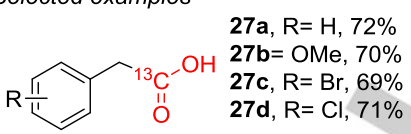<smiles>O=C(O)c1ccc(C[As](=O)O)cc1</smiles><smiles>Cc1ccc(C(=O)Nc2ccc(C[As](=O)O)cc2)cc1C</smiles>

27f, $80 \%$

$27 g, 46 \%$

27h, $21 \%$<smiles>COc1ccc2cc(C(C)[13C](=O)O)ccc2c1</smiles>

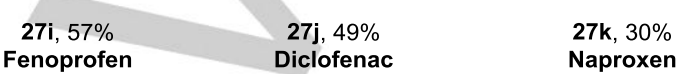

Scheme 29. Carbon isotope exchange developed by the groups of Audisio
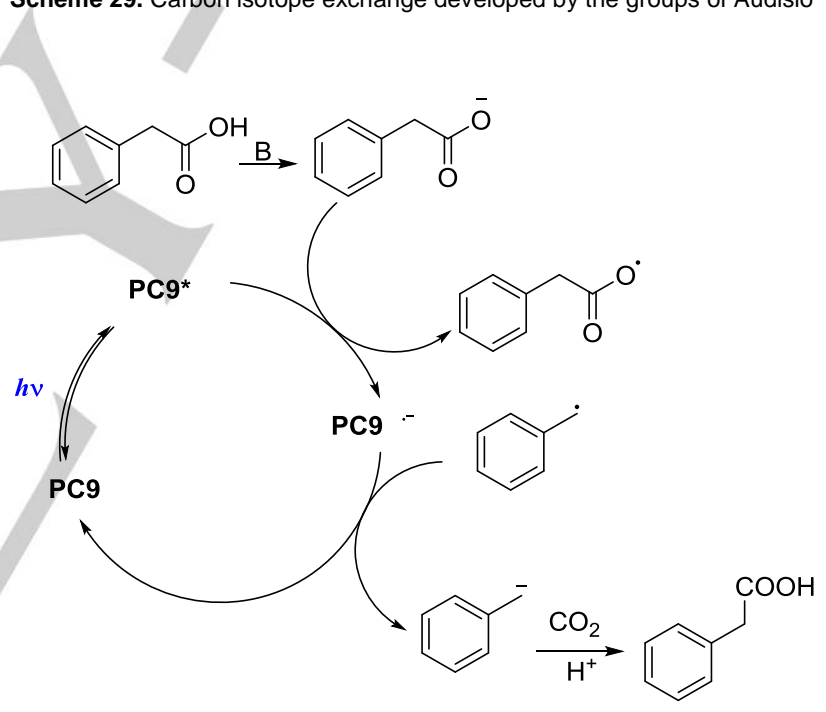

Scheme 30. Carbon isotope exchange developed by the groups of Audisio

\subsubsection{Functionalisation of alkenes}

The difunctionalization of alkenes with $\mathrm{CO}_{2}$ and radical sources have been undertaken by several research groups. The first example of hydrocarboxylation of enamides and imines with $\mathrm{CO}_{2}$ has been reported by the group of $\mathrm{Yu}$ (Scheme 31, eq 1). ${ }^{[44]} \mathrm{PC9}$ was used as photocatalyst in the presence of mixture of $\mathrm{Cs}_{2} \mathrm{CO}_{3}$ and ${ }^{i} \mathrm{Pr}_{2} \mathrm{NEt}$ and the reactions have been performed in DMF at room temperature upon blue LEDs irradiation. In order to demonstrate the versatility of the protocol the authors demonstrated that the reaction could be easily scalable under atmospheric pressure of $\mathrm{CO}_{2}$. The group of $\mathrm{Wu}$ disclosed $\mathrm{C}-\mathrm{Si}$ and $\mathrm{C}-\mathrm{C}$ bond formation through activation of $\mathrm{Si}-\mathrm{H}$ bond and $\mathrm{C}$ $\mathrm{H}$ bond. ${ }^{[45]}$ The key to success is the use of quinuclidine-3-yl acetate co-catalyst $(20 \mathrm{~mol} \%)$ acting as hydrogen-atom-transfer catalyst. The reactions were performed in DMSO at room temperature under atmospheric pressure of $\mathrm{CO}_{2}$ (Scheme 31 
eq 2). Similarly, the group of $Y u$ reported phosphonocarboxylation of enamides and styrenes and acrylates derivatives providing a straightforward access to $\beta$ phosphono carboxylic acids. ${ }^{[46]}$ The reactions were performed in DMF in the presence of $\mathrm{Cs}_{2} \mathrm{CO}_{3}$ or $\mathrm{K}_{2} \mathrm{CO}_{3}$ as base (Scheme 31, eq 3). Afterwards, Chen, Xi and co-workers demonstrated that $\gamma$ amino acids could be obtained through dicarbofunctionalisation of styrenes with amines and $\mathrm{CO}_{2}$ (Scheme 31, eq 4). ${ }^{[47]}$ The strategy is based on the generation of $\alpha$-aminoalkyl radical after oxidation of the amine followed by deprotonation. A variety of styrenes and dialkylanilines derivatives have been converted to their corresponding products. Finally, the group of $\mathrm{Yu}$ demonstrated that PC9 is also an effective catalyst for the arylcarboxylation of indoles. The driving force of this reaction is the carboxylative dearomatisation of indoles. ${ }^{[48]}$ The reactions were performed in DMSO in the presence of $\mathrm{Cs}_{2} \mathrm{CO}_{3}$ and DIPEA as sacrificial reductant (Scheme 31, eq 5).

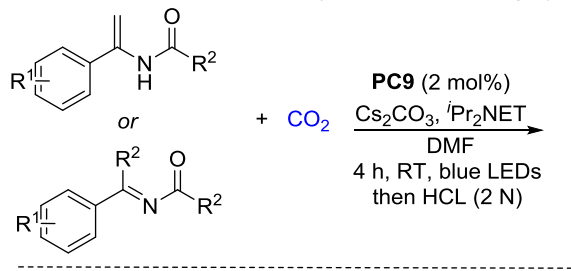

$$
\underbrace{37 \text { examples }}_{\substack{68 \\ 60-95 \%}}
$$

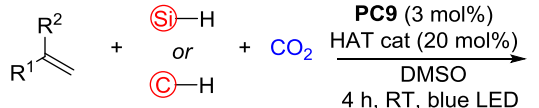

$$
\begin{aligned}
& 42 \text { examples } \\
& 30-77 \%
\end{aligned}
$$

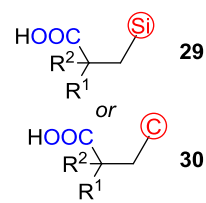

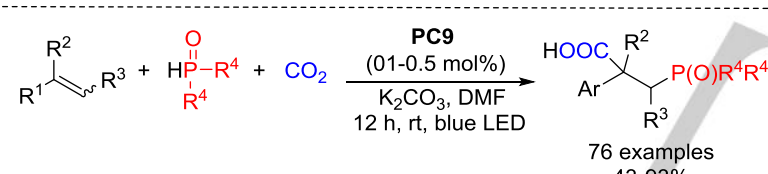

$$
\begin{aligned}
& \text { 43-93\% }
\end{aligned}
$$$$
\text { (4) }
$$$$
22 \text { examples }
$$

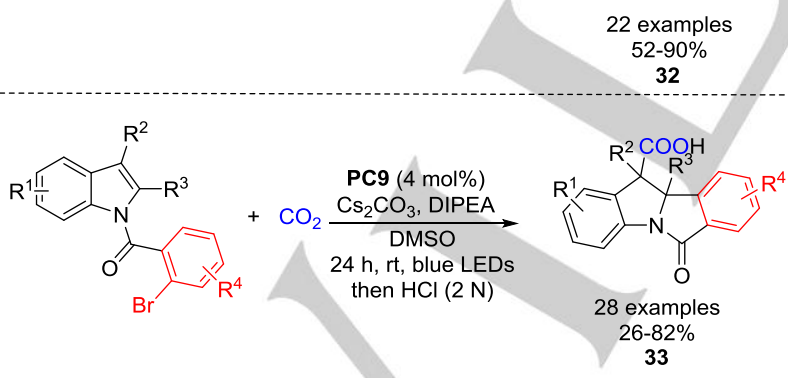

Scheme 31. Difunctionalization of alkenes with $\mathrm{CO}_{2}$ and radical sources

The difunctionalization of vinyl ureas was undertaken by the group of Clayden. ${ }^{[49]}$ Herein, PC9 (1-5 mol\%) allows the fluoroalkylation or phosphorylation of vinyl ureas under mild reaction conditions and the desired products were obtained in good to excellent yields using $\mathrm{Cs}_{2} \mathrm{CO}_{3}$ as base and blue LED as irradiation source at $30^{\circ} \mathrm{C}$. The key to success is an intramolecular $\mathrm{S}_{N} \mathrm{Ar}$ (Truce-smiles) mechanism. In addition, the authors assume the formation of anionic intermediate responsible for the aryl migration from a C-N bond to form a new C-C bond (Scheme 32). In this context, the oxidation of the sulfonate or the phosphine by the excited photocatalyst allows the formation of a new radical $\left(R^{*}\right)$ and reduced organophotocatalyst $\left(\mathbf{P C 9}^{-}\right)$. This later collapses to the starting vinyl ureas to form a new radical. Afterwards a reduction is occurring to form a new anion and regenerate the photocatalyst. Finally, a concerted intramolecular $\mathrm{S}_{N} \mathrm{Ar}$ (Truce-Smiles rearrangement) is taking place to afford the desired product. The authors performed a series of experiments in order to confirm the proposed mechanism. For instance, the presence of TEMPO inhibits completely the reactivity and no product formation was observed. It should be mentioned also that the Sterm-Volmer studies confirmed that Langlois reagent $\left(\mathrm{CF}_{3} \mathrm{SO}_{2} \mathrm{Na}\right)$ quenches the fluorescence of the excited photocatalyst. Furthermore, performing the reaction starting with a vinyl urea bearing dialkylated amine, cannot undergo rearrangement. The presence of $\mathrm{D}_{2} \mathrm{O}$ also allows a significant incorporation of deuterium, thus confirming the formation of an anionic intermediate. Finally, the measurement of quantum yield supports a stepwise mechanism ( $\phi$ of 0.18 ).

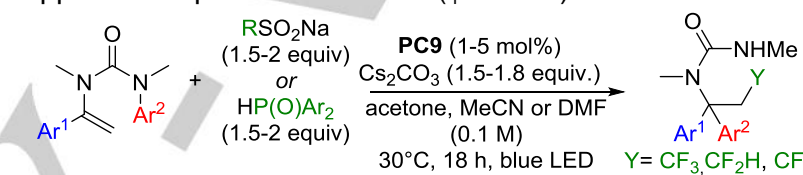
P(O)AR
Selected examples
34
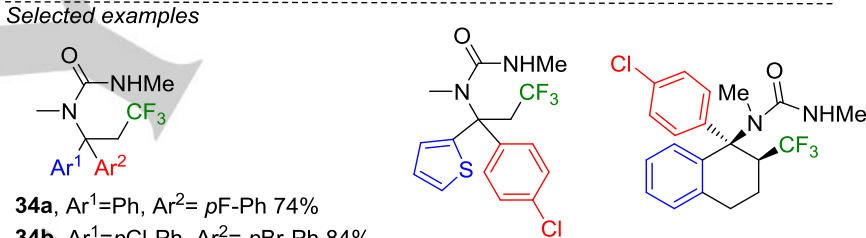

34a, $\mathrm{Ar}^{1}=\mathrm{Ph}, \mathrm{Ar}^{2}=p \mathrm{~F}-\mathrm{Ph} 74 \%$

34b, $\mathrm{Ar}^{1}=p \mathrm{Cl}-\mathrm{Ph}, \mathrm{Ar}^{2}=p \mathrm{Br}-\mathrm{Ph} 84 \%$

34c, $\mathrm{Ar}^{1}=p \mathrm{Cl}-\mathrm{Ph}, \mathrm{Ar}^{2}=p \mathrm{CO}_{2} \mathrm{Et}-\mathrm{Ph} 80 \%$

34f, $45 \%$

34g, $68 \%$

34d, $\mathrm{Ar}^{1}=p \mathrm{l}-\mathrm{Ph}, \mathrm{Ar}^{2}=p \mathrm{Cl}-\mathrm{Ph} 80 \%$

$>20: 1$ d.r

34e, $\mathrm{Ar}^{1}=p \mathrm{OCF}_{3}-\mathrm{Ph}, \mathrm{Ar}^{2}=p \mathrm{Cl}-\mathrm{Ph} 80 \%$

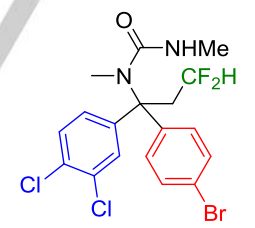

34h, $76 \%$

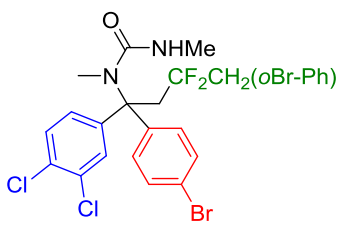

$34 \mathbf{i}, 94 \%$

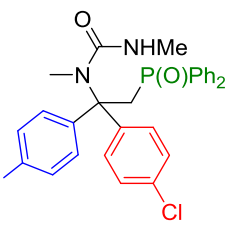

34j, $64 \%$

$$
\text { Proposed mechanism }
$$

Scheme 32. Organophotocatalytic difunctionalization of vinyl ureas developed by the group of Clayden

The group of Waser also studied the difunctionalization of unsaturated compounds. Oxyalkynylation of ene-carbamates and enol ethers was undertaken by using Ethynyl BenziodoXolones (EBXs) to form 1,2-amino alcohols and 1,2diols. ${ }^{[50]}$ Herein, 2 mol \% of the organophotocatalyst (PC17, 4CICzIPN) were sufficient to obtain good to excellent yields of the desired compounds. Catalytic amount of acetoxy 
benziodoxolones (BIOAc, $20 \mathrm{~mol} \%$ ) turns out to be beneficial for the reaction to perform with good efficiency in DCM at room temperature under blue LED irradiation (Scheme 33). Noteworthy, high functional group tolerance was observed under these conditions including terminal alkene, ester chloride in the starting ene-carbamates and enol ethers. Also, to some extent substituted aryl acetylene were also tolerated including ester as well as halogenated starting materials. Afterwards, mechanistic investigations were performed, herein Sterm-Volmer experiments confirmed that the starting ene-carbamates quenches the fluorescence of the excited photocatalyst yielding a new radical cation and reduced catalyst (PC17 $\left.{ }^{--}\right)$. It should be mentioned that the photocatalyst can also reduce BIOAc in the initiation process, which reflects the ability of cyanoarenes to oxidize and reduce substrates. The radical cation is trapped by the carboxylate to form a new radical. This later reacts with EBXs to afford the desired product as well as iodanyl radical. Finally, the catalyst is regenerated after reduction of iodanyl radical to form carboxylate (Scheme 34 ).

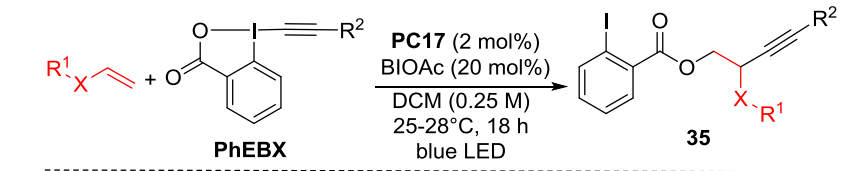

$$
\text { Selectes examples }
$$<smiles>CN(C(=O)OCc1ccccc1)C(C#Cc1ccccc1)COC(=O)c1ccccc1I</smiles><smiles>C=CCN(C(=O)OC(C)(C)C)C(C#Cc1ccccc1)COC(=O)c1ccccc1I</smiles>

$35 a, 80 \%$<smiles>CCOC(=O)CCN(C(=O)OCC)C(C#Cc1ccccc1)COC(=O)c1ccccc1I</smiles>

35b, $83 \%$

$35 c, 83 \%$

$35 d, 69 \%$<smiles>C=CCOC(C#Cc1ccccc1)COC(=O)c1ccccc1I</smiles><smiles>O=C(O)c1ccccc1I</smiles>

35 e, $45 \%$

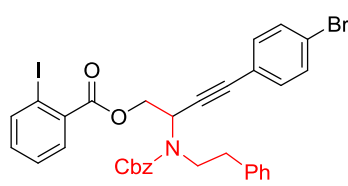

35g, $76 \%$

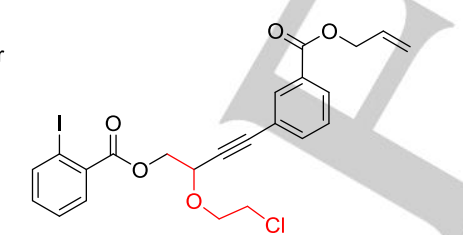

$35 \mathrm{~h}, 37 \%$
Scheme 33. Organophotocatalytic 1,2-oxyalkynylation of ene-carbamates and enol ethers using Ethynyl BenziodoXolones (EBXs) developed by the group of Waser

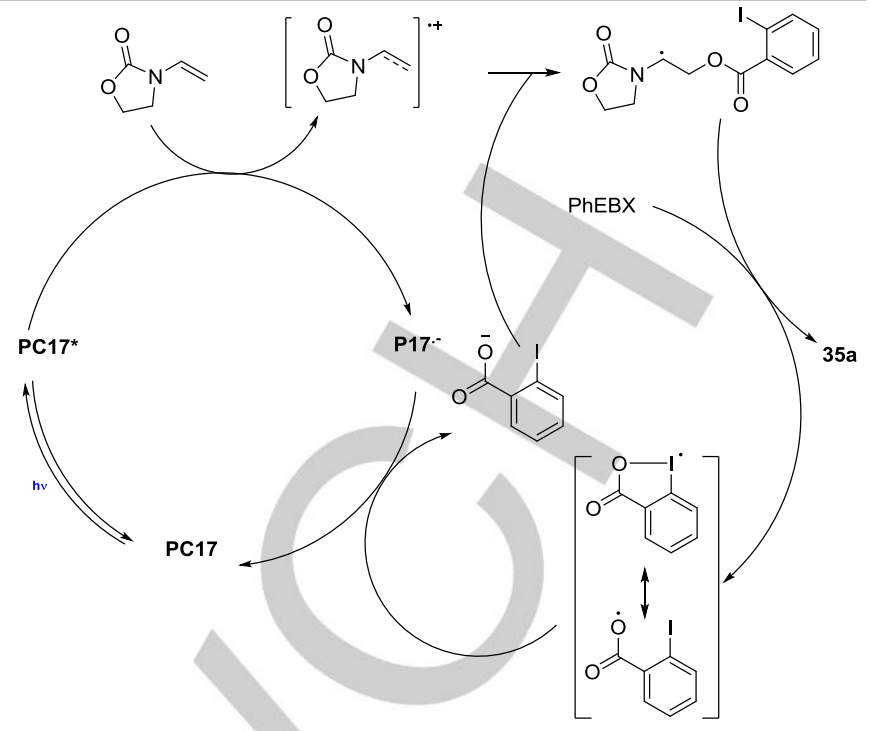

Scheme 34. Proposed mechanism for the organophotocatalytic 1,2 oxyalkynylation of ene-carbamates and enol ethers

In the context of formation of C-Si bond, the group of Wang and Uchiyama demonstrated that silacarboxylic acids are precursors of silyl radical by using PC9 as photocatalyst upon blue LEDs irradiation. ${ }^{[51]}$ The hydrosilylation of alkenes takes place at room temperature in MeCN as a solvent. A variety of activated alkenes and styrenes could be converted to their corresponding silylated product in moderate to excellent yields. Mechanistic investigations starting with the quantum yield support a stepwise mechanism ( $\phi$ of 0.04 ) (Scheme 35).

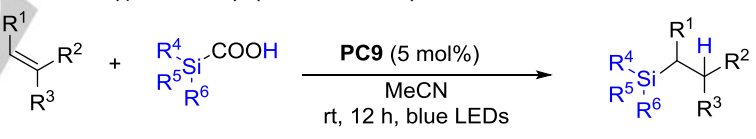

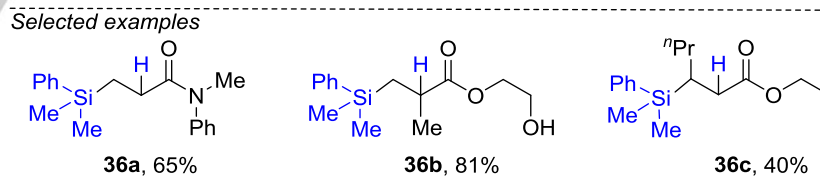

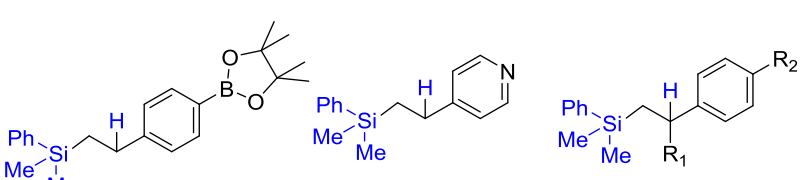
$36 \mathrm{~d}, 65 \%$

$36 \mathbf{e}, 80 \%$

36f, $R^{1}=\mathrm{Me}, \mathrm{R}^{2}=$ COOEt $45 \%$ 36g, $R^{1}=P h, R^{2}=F 85 \%$

Scheme 35. Hydrosilylation of alkenes by using Silacarboxylic acids developed by the group of Wang and Uchiyama

The authors proposed the following mechanism, the carboxylate is able to reduce the excited photocatalyst yielding a new silyl carboxylate radical species able after decarboxylation to form the silyl radical. This latter collapses with the alkene yielding a new carbon centered radical. The reduced photocatalyst is oxidized by this new carbon centered radical yielding to a new anion and regenerating the photocatalyst. This anion can deprotonate the starting material forming the 
hydrosilylated product. Interestingly, labeled products were obtained with $\mathrm{D}_{2} \mathrm{O}$ (Scheme 36 ).

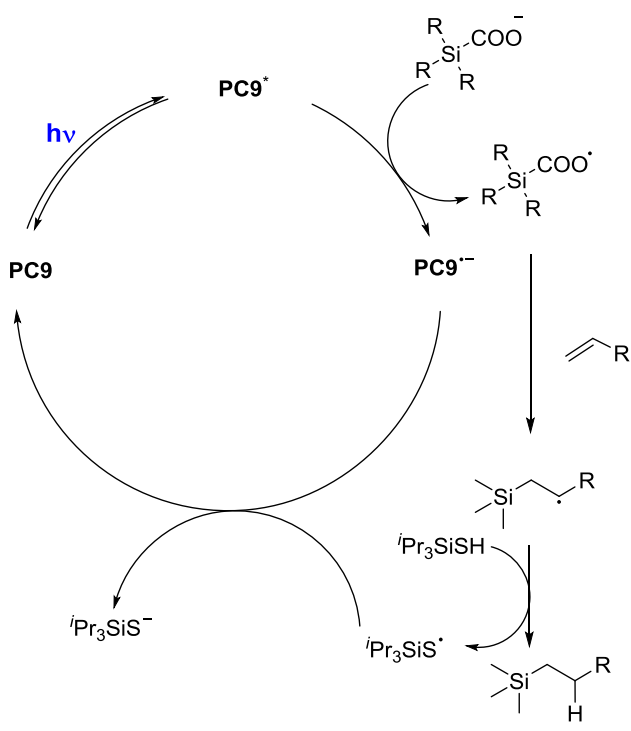

Scheme 36. Proposed mechanism for the hydrosilylation of alkenes.

Very recently, the group of Yamashita and Kobayashi developed a C-C coupling between malonates and styrenes. ${ }^{[52]}$ The reactions were performed at room temperature in $\mathrm{MeCN}$ as solvent under blue LED irradiation (Scheme 37). Herein, the key to success is the association of catalytic amount of $\mathrm{KOtBu}(5$ mol\%) able to deprotonate the malonates generating catalytic amounts of enolate. This latter is oxidized by the excited photocatalyst (PC9) upon SET to form the corresponding radical. After, a recombination with the alkene is tacking place to form a new stable benzylic radical. Afterwards, the organophotocatalyst is regenerated upon reduction of the radical to form a new carbanion (Scheme 38). It should be mentioned that performing the reaction in deuterated acetonitrile did not lead to any deuterium incorporation. Also, using the more reducing PC14 was beneficial for the reaction outcome and showed better reactivity especially with alkenes bearing electron-donating group.

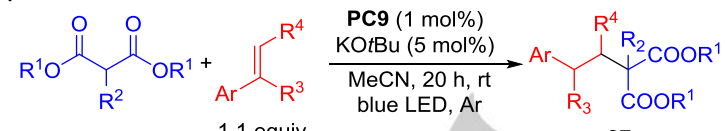

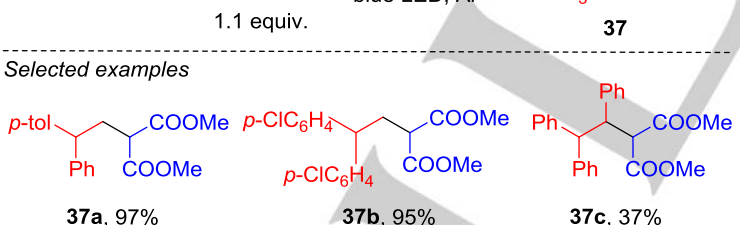

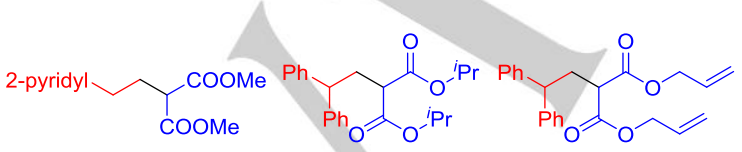

37d, $80 \%$

37 e, $99 \%$

37f, $18 \%$

Scheme 37. Photoinduced C-C bond formation reaction of malonates with Styrenes developed by the group of Yamashita and Kobayashi.

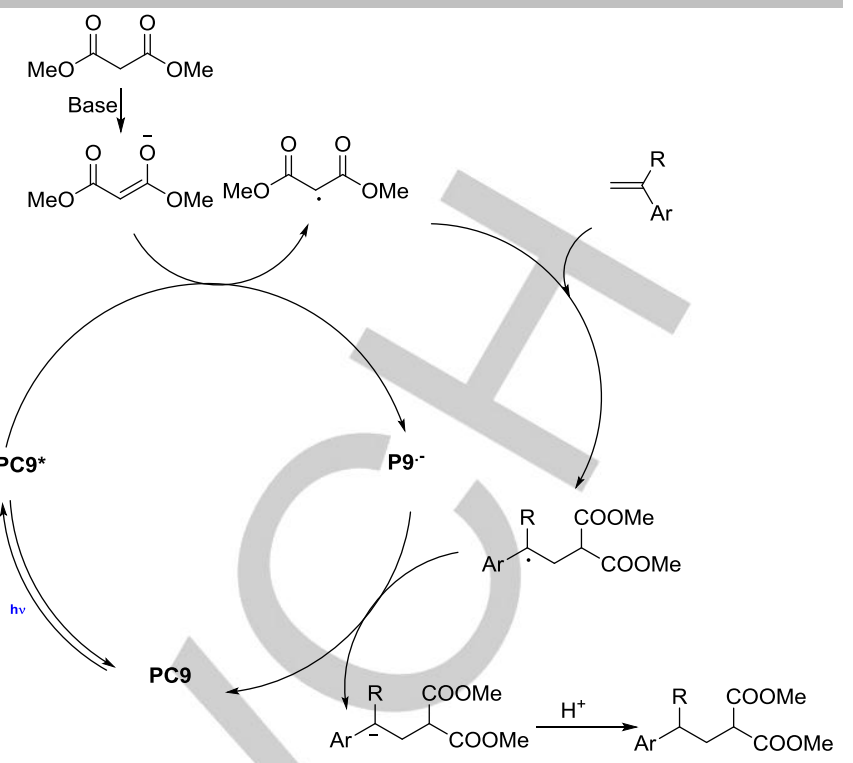

Scheme 38. Proposed mechanism for the photoinduced C-C bond formation reaction of malonates with styrenes.

Very recently, the group of $\mathrm{Li}$ reported a metal-free difunctionalization of alkenes with alkyl formates and $N$ alkoxyazinium salts to access value-added $\beta$-alkoxy, $\beta$ hydroxy, $\beta$-formyloxy, and $\beta$-dimethoxymethoxy alkanoates using PC9 as the photocatalyst (Scheme 39). ${ }^{[33]}$ The reaction features high functional group tolerance and high efficiency.

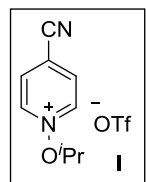

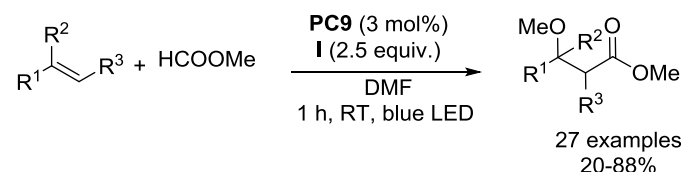
38

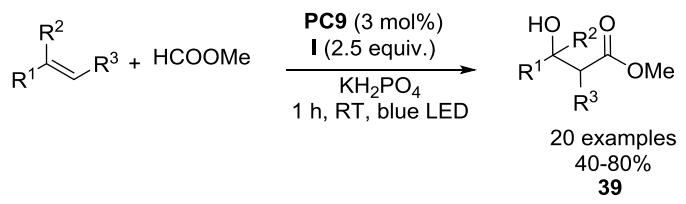

Scheme 39. Difunctionalization of alkenes with alkyl formates and $N$ alkoxyazinium. 
Mechanistically, the reaction starts with the single electron reduction of the alkoxyazinium salt with the excited state of the photocatalyst to generate the isopropoxy radical. The latter abstrats a hydrogen from the methyl formate to generate the ethoxycarbonyl radical that adds to the alkene to form the corresponding carbon-centered radical. A subsequent oxidation with the oxidized state of the photocatalyst $\left(\mathbf{P C 9}^{--}\right)$generate the carbocation that is immediately intercepted with methanol to yield the final difunctionalized adduct (Scheme 40).

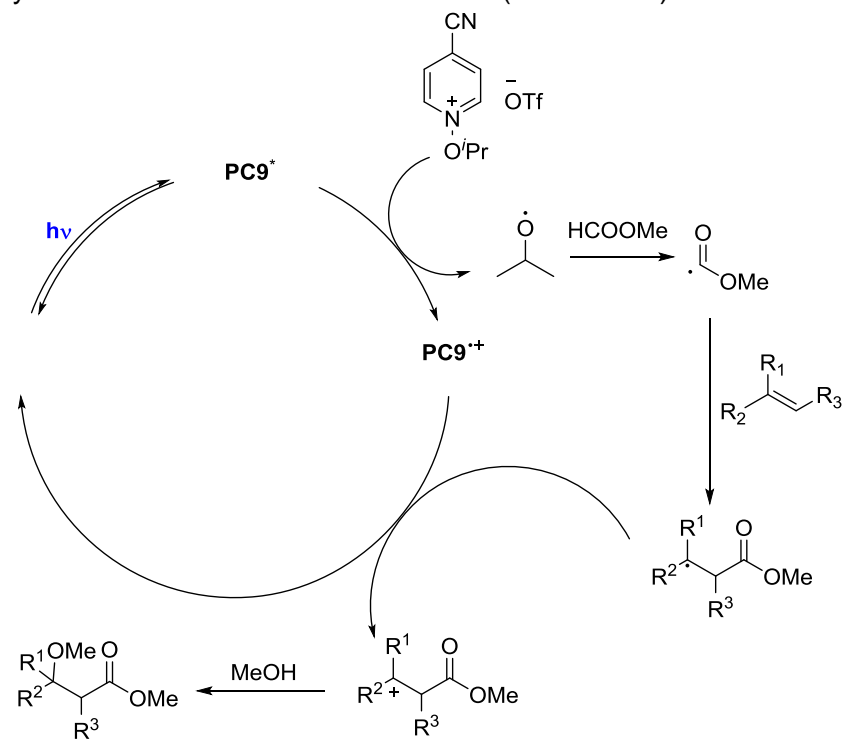

Scheme 40. Proposed mechanism for the difunctionalization of alkenes with alkyl formates and $\mathrm{N}$-alkoxyazinium.

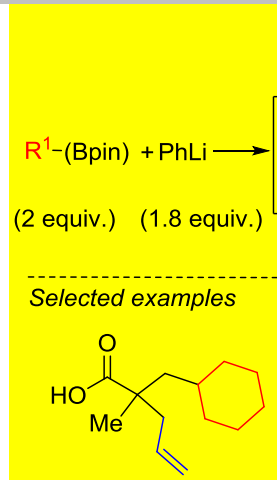

$\mathbf{X X a}, 77 \%$

$\mathrm{mmol} \mathrm{scale}$<smiles>C=CCC(C)(CC(CC)CC)C(=O)O</smiles>

XXd, $69 \%$<smiles>C=C(Cl)CC(CC1CCCCC1)(C(=O)O)C(=O)O</smiles>

XXf, $51 \%$<smiles>C=CCC(C)(CC1CCN(C(C)(C)C)CC1)C(=O)O</smiles>

$\mathbf{X X b}, 60 \%$ $\rightarrow \mathrm{HO} \underset{\mathrm{Me}}{\stackrel{\mathrm{O}}{\mathrm{N}} \mathrm{R}^{2}} \mathrm{R}^{1}$ $\mathbf{X X}$
$\mathbf{X X c}, 76 \%$<smiles>C=CCC(C)(CC1CCC(F)(F)CC1)C(=O)O</smiles><smiles>C=CC(C)(CC(C)(C)CCCOc1cc(C)ccc1C)C(=O)O</smiles>

$\mathbf{X X e}, 76 \%$

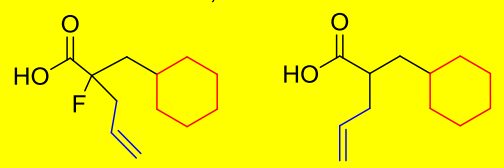

XXh, $43 \%$

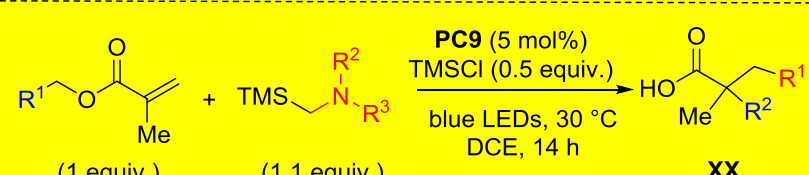

(1 equiv.)

(1.1 equiv.)

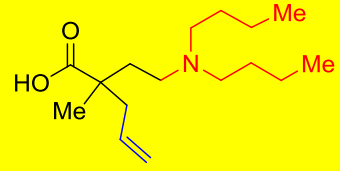

XXd, $57 \%$

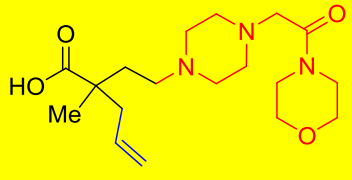

$\mathbf{X X d}, 53 \%$

Scheme 41. 1,2-dialkylation of $\alpha$-substituted acrylates developed by the group of Glorius.

\subsection{3 $\mathrm{C}\left(s p^{2}\right)-\mathrm{X}$ bond activation for the formation of $\mathrm{C}-\mathrm{C}$ bond}

The Jui group recently demonstrated that intramolecular hydroarylation of arenes could be performed with organic photoredox catalyst PC11 (Scheme 42). ${ }^{[54]}$ The use of sacrificial electron donor DIPEA (Hünig's base) able to reduce the excited photocatalyst turns out to be detrimental for the feasibility of the reaction. It should be mentioned that Stern-Volmer experiments confirmed this electron transfer. Afterwards, the reduced photocatalyst is able to transfer an electron to the starting aryl halide. Subsequently, cyclization through 5-exo-trig mode will take place generating cyclohexadienyl radical. The reduction of the newly formed radical allows the formation of dienyl anion. Finally, a protonation is taking place to form the desired hydroarylated arene. The reactions were performed in a mixture of MeCN and water upon blue LEDs irradiation and the desired product were formed in good to excellent yield. Interestingly, and in order to demonstrate the utility of the developed methodology, 
the authors demonstrated that such conditions could be applied for the straightforward synthesis of NPY Y5 receptor antagonist.

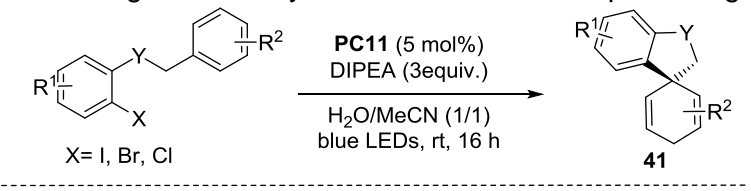

Selected examples
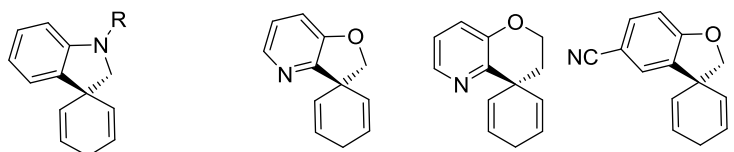

41a, $\mathrm{R}=\mathrm{SO}_{2} \mathrm{Me}, \mathrm{X}=\mathrm{I}, 65 \%$ 41c, $\mathrm{X}=\mathrm{Br}, 72 \%$ 41d, $\mathrm{X}=\mathrm{Br}, 46 \%$ 41e, $\mathrm{X}=\mathrm{Cl}, 54 \%$ 41b, $R=B o c, X=B r, 79 \%$<smiles>COC1=CC2(C=C(F)C1)C(=O)N(C)c1ccccc12</smiles><smiles>CN1C(=O)[C@]2(C=C(F)Cc3ncccc32)c2ccccc21</smiles><smiles>OC1C=CC2(C=C1)COc1cccnc12</smiles>

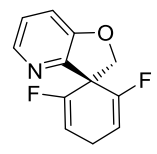

$\mathrm{OH}$
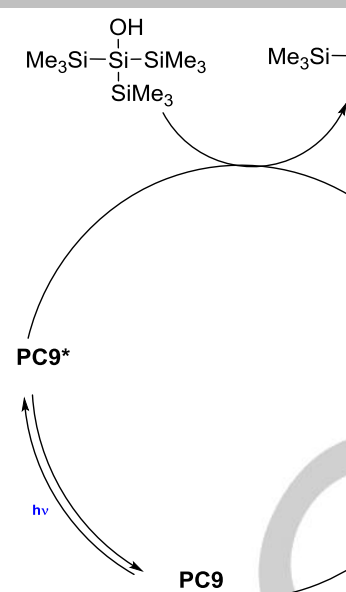

PC9

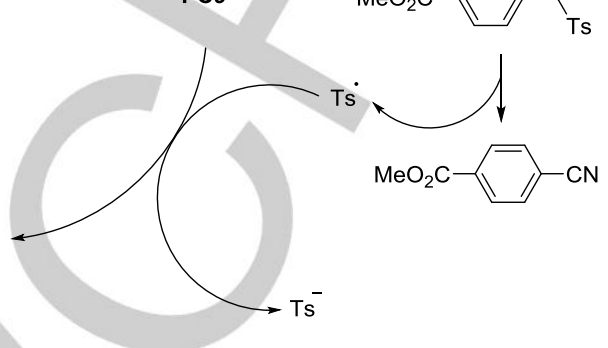

Scheme 43. Proposed mechanism for the cyanation of bromoarenes.

\subsection{4 $\mathrm{C}\left(\mathrm{sp}_{2}\right)$-heteroatom bond formation}

In order to leverage the orthogonality of transition metal catalysed selective $\mathrm{C}-\mathrm{N}$ bond forming process through radicalradical cross-coupling process. The group of Wu showed very recently that the formation of $\mathrm{C}\left(s p^{2}\right)-\mathrm{N}$ bond formation could be performed under metal-free photoredox catalysis. ${ }^{[56]}$ PC11 was used as organic photocatalyst for the coupling of cyanoheteroarenes and amines. The reaction scope encompasses a variety of primary and secondary aliphatic as well as aromatic amines and the desired coupling products were obtained in good to excellent yield (Scheme 44). The authors deeply investigated the reaction mechanism. In this context, the authors confirmed that excitation of organophotocatalyst gave rise to thermally assisted delayed fluorescence (TADF) emission at $530 \mathrm{~nm}$ which is quenched by the amine. Herein, thanks to flash photolysis investigation, the authors were able to confirm the presence of amine radical cation as well as the photocatalyst radical anion ( $\mathrm{PC}_{11}{ }^{-}$). It should be mentioned that the excited photocatalyst could not be quenched by the cyanopyridine since no changes was observed when this later was introduced in a solution of the excited photocatalyst. Afterwards, the formed radical anion ( $\mathbf{P C 1 1}^{-}$) delivers an electron to the cyanopyridine to regenerate the organophotocatalyst to its ground state and the aryl radical anion. This later react with the amine radical cation to deliver the $\mathrm{C}-\mathrm{N}$ coupling product after elimination of cyanide. Interestingly the presence of DABCO is not only to neutralize the formed $\mathrm{HCN}$ but could also be involved in product formation. Indeed, DABCO could play a role of relay by reducing the excited photocatalyst and form $\mathrm{DABCO}^{*+}$. The formed radical cation oxidizes the amine and regenerates itself (Scheme 45). 


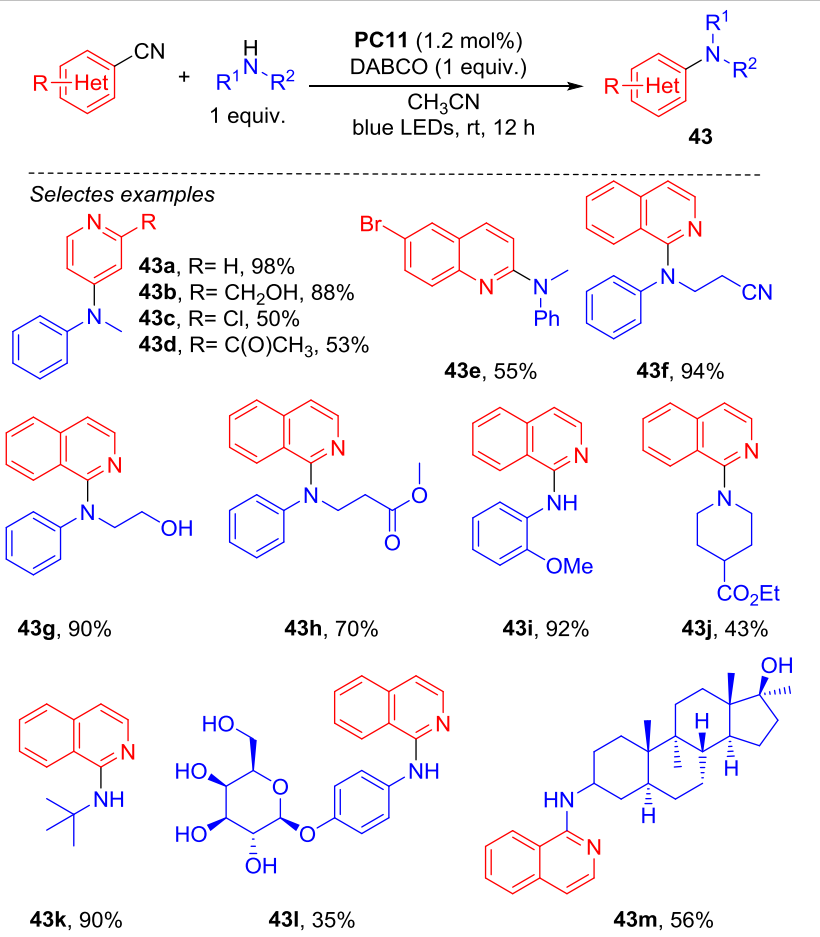

Scheme 44. Photoinduced $\mathrm{C}-\mathrm{N}$ bond via radical-radical cross-coupling developed by the group of $\mathrm{Wu}$.

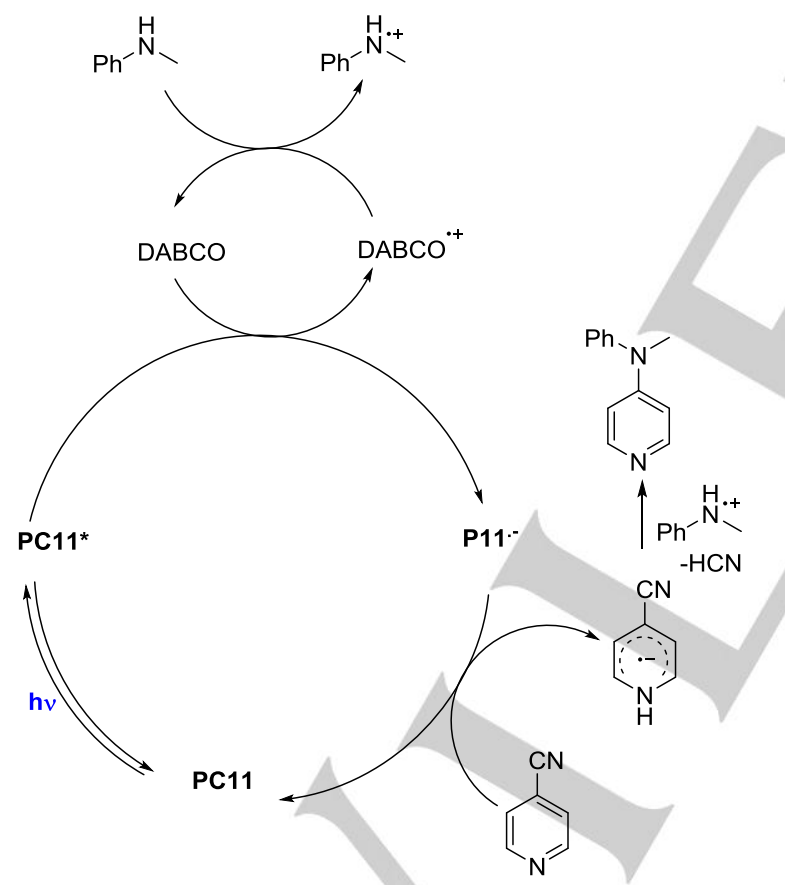

Scheme 45. Proposed mechanism for the photoinduced C-N bond via radicalradical cross-coupling developed by the group of $\mathrm{Wu}$.

Very recently, the groups of Wolf and Zeitler developed a straightforward metal free procedure for the direct access to tertiary phosphines as well as quaternary phosphonium salts. ${ }^{[57]}$ The authors demonstrated that primary as well as secondary phosphines could be arylated or alkylated by using aryl halides or alkyl halides, respectively. The key to success is the use of PC11 as organophotocatalyst upon blue LED irradiation. The reactions were performed in the presence of $\mathrm{Et}_{3} \mathrm{~N}$ or DIPEA in $\mathrm{MeCN}$ (Scheme 46). Of further interest, the authors demonstrated that these conditions also allow the direct access to symmetrical aryl phosphines and phosphoniums salts by starting from white phosphorus (P4).
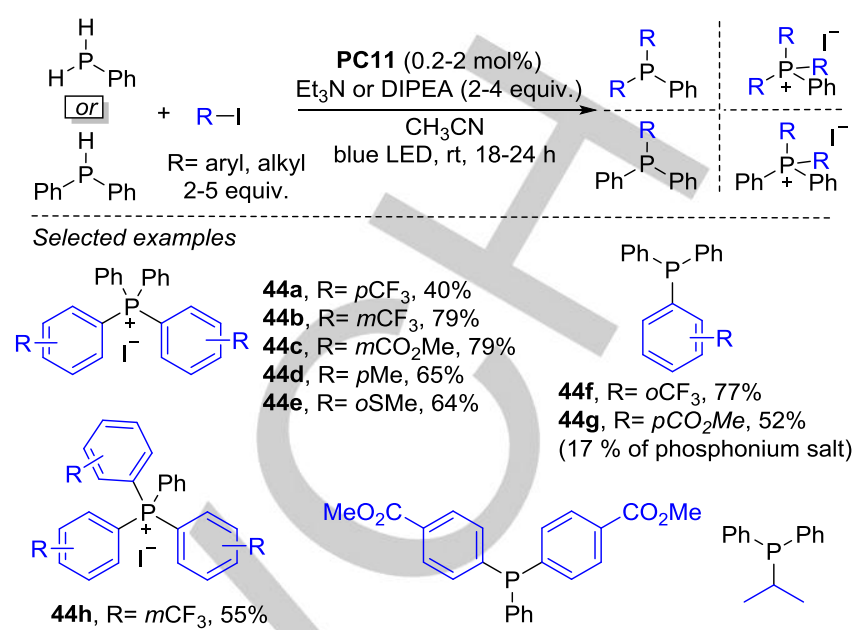

$44 \mathrm{~h}, \mathrm{R}=m \mathrm{CF}_{3}, 55 \%$

$44 \mathrm{i}, \mathrm{R}=m \mathrm{CO}_{2} \mathrm{Me}, 55 \%$

$44 k, 32 \%$

44I, $R=94 \%$

44j, $\mathrm{R}=m \mathrm{OMe}, 50 \%$

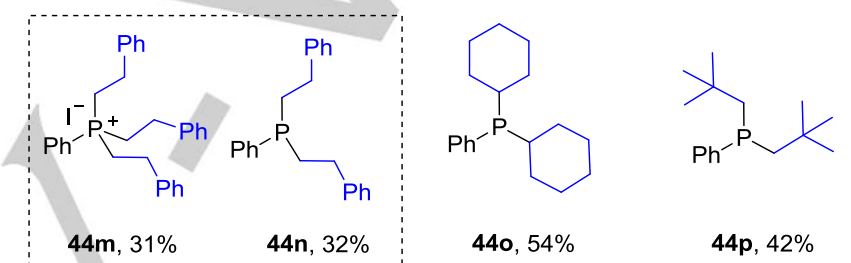

Scheme 46. Photoinduced synthesis of unsymmetrical phosphines and phosphonium salts developed by the groups of Wolf and Zeitler.

Performing the reaction in the presence of TEMPO was detrimental for the reaction outcome since no product formation occurred. ${ }^{31} \mathrm{P}$ NMR studies reveal that when the reaction is started with $\mathrm{HPPh}_{2}$, a full conversion to $\mathrm{P}_{2} \mathrm{Ph}_{4}$ is taking place within 2 hours. This intermediate was not formed in the absence of the alkyl halides. In this context the authors assume that the reduced alkyl halide abstracts an $\mathrm{H}$ atom from the starting phosphine. The formed phosphorus radical dimerizes to form the $\mathrm{P}_{2} \mathrm{Ph}_{4}$ intermediate. The $\mathrm{P} 2$ intermediate reacts with the cyclohexyl radical to form the desired product. Overall, the presence of amine serves as electron donor to excite the organophotocatalyst forming the radical anion photocatalyst. This later is able to reduce the alkyl halides which reacts with the P2 phosphorus intermediate (Scheme 47).

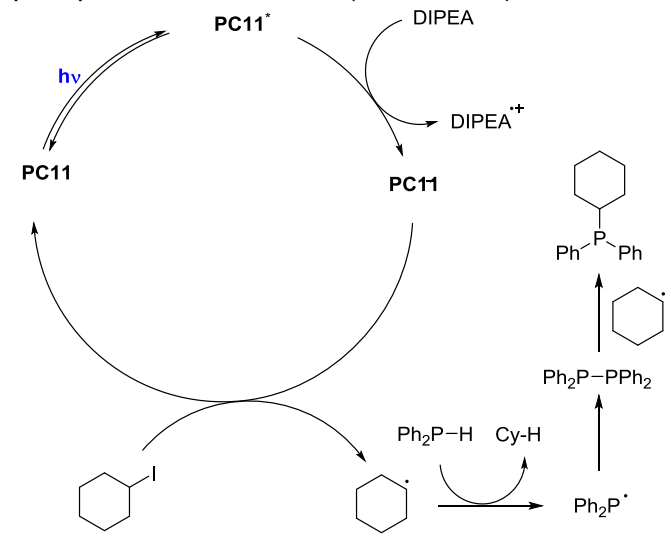

Scheme 47. Proposed mechanism for photoinduced synthesis of unsymmetrical phosphines and phosphonium salts 
The direct synthesis of phosphorylated phenanthridine, quinolines and benzothiazoles was undertaken recently by Chen, $\mathrm{Yu}$ and their co-workers. ${ }^{[58]}$ The authors investigated the impact of oxydo/redox potential of cyanoraenes photocatalyst based on the nature of the substituent on the donor part of the catalyst. It turns out that carbazole substituted with electron donating group have lower oxidizing ability than those substituted with electron withdrawing group. Thus, PC17 turns out to be the best catalyst for the generation of phosphorous-centered radical a key parameter in the generation of the desired phosphorylated heterocycle (Scheme 48).

$$
\text { (1) }
$$$$
\text { (2) }
$$$$
45
$$

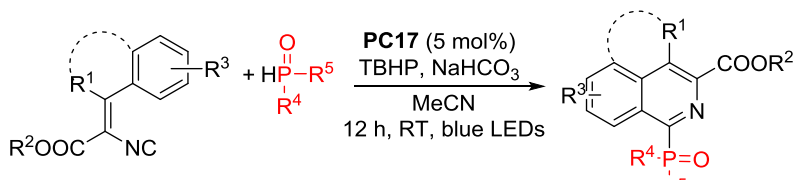

$$
\begin{aligned}
& \mathrm{R}^{5} \\
& 14 \text { examples } \\
& 33-68 \%
\end{aligned}
$$

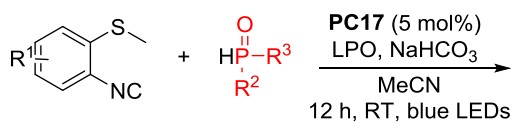

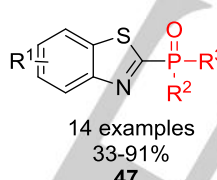

Scheme 48. Synthesis of phosphorylated heterocycle developed by the group of Chen, Yu and their co-workers.

From a mechanistic point of view, the authors proposed the following mechanism, the excited photocatalyst is able to oxidize deprotonated starting phosphine confirmed by EPR spectroscopy. The formed radical collapses to the phenanthridine yielding a new radical. The photocatalytic cycle is closed by TBHP yielding tertbutoxide radical. This latter is able to oxidize the phosphorylated radical whish deliver the desired product after radical cascade cyclization and deprotonation (Scheme 49).

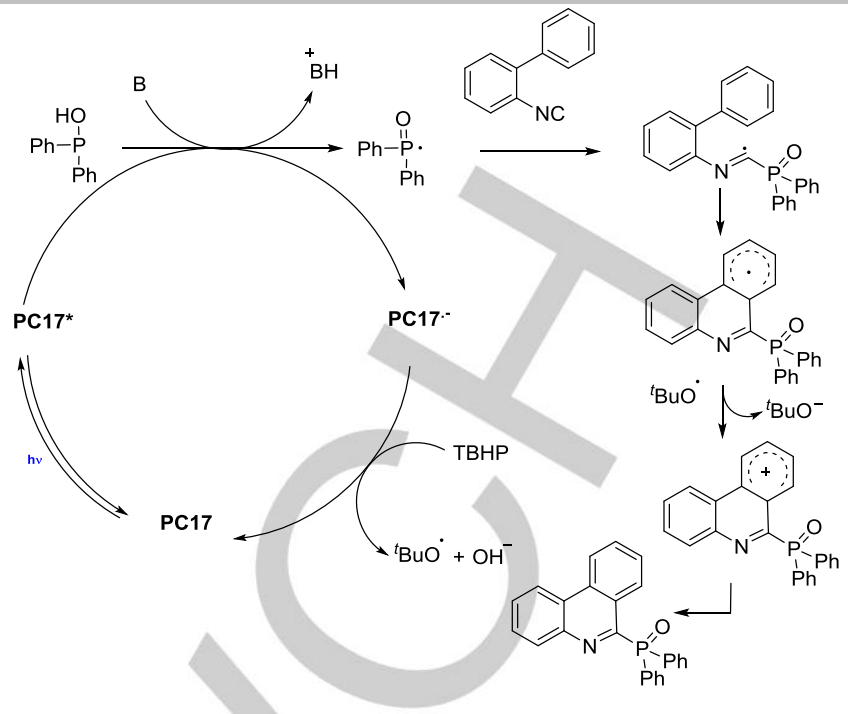

(1) Scheme 49. Proposed mechanism for the synthesis of phosphorylated heterocycle

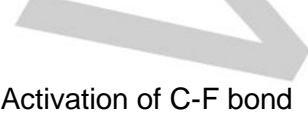

\subsubsection{Activation of $\mathrm{C}-\mathrm{F}$ bond}

The group of Gouverneur demonstrated recently that the hydrodefluorination of trifluromethylarenes to form difluormethylarenes could take place under organophotoredox catalysis. ${ }^{[59]}$ Due to its high reduction ability $\left(\mathrm{E}_{\text {red }}=-1.52 \mathrm{~V}\right)^{[60]}$, 4DPAIPN (PC18, 2,4,5,6-tetrakis(diphenylamino)isophtalonitrile, $2.5 \mathrm{~mol} \%$ ) was the organophotocatalyst of choice to perform the desired transformation under blue LED irradiation. The reactions were performed with a combination of 2,2,6,6tetramethylpiperidine (TMP) and 1,2,2,6,6-pentamethylpiperidine (PMP) and 4-hydroxythiophenol (4-HTP) in 1,2-dichloroethane (DCE). Several functional groups were tolerated and the desired compounds were obtained in moderate to very good yield with good to excellent selectivity $\left(\mathrm{CF}_{2} \mathrm{H} / \mathrm{CH}_{2} \mathrm{~F}\right.$ ratio) (Scheme 50 ). Interestingly, the authors demonstrated that the reaction could be scaled-up using continuous-flow chemistry. 


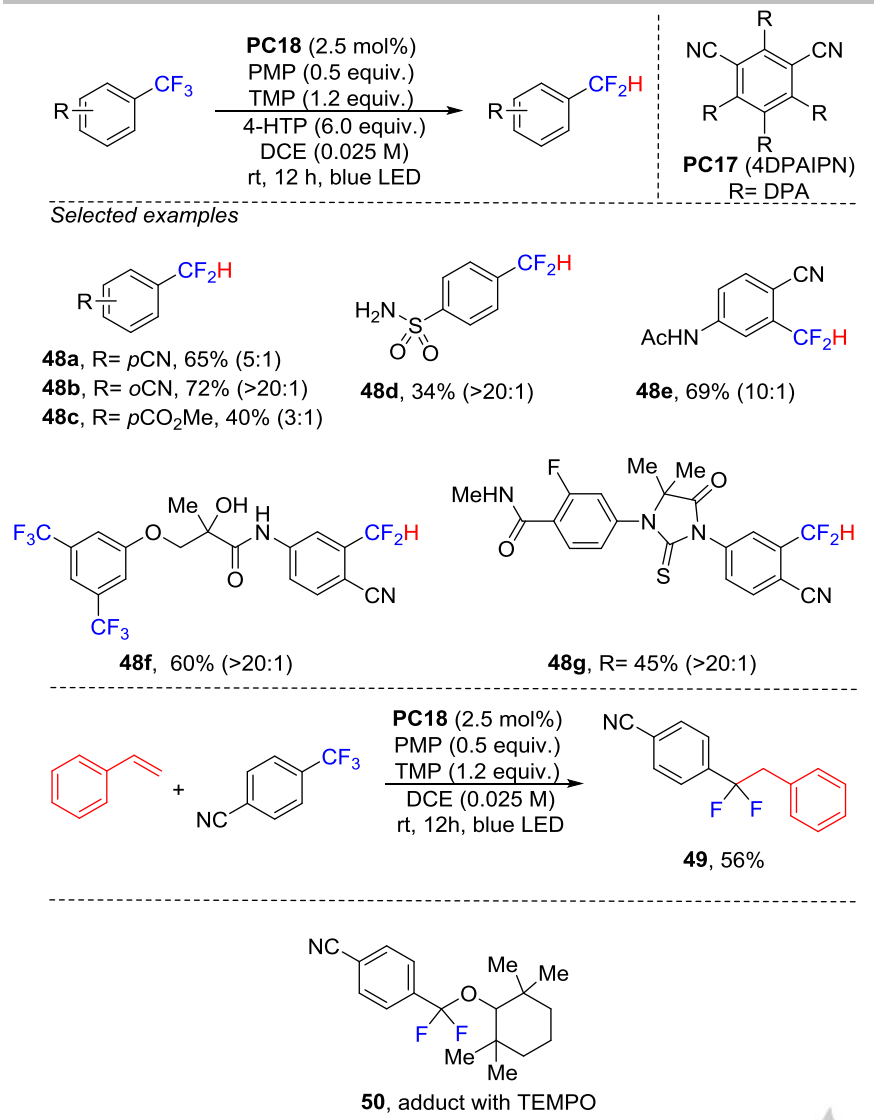

Scheme 50. Organophotocatalytic hydrodefluorination of trifluormethylarenes developed by the group of Gouverneur. Yields of $\mathrm{CF}_{2} \mathrm{H} / \mathrm{CH}_{2} \mathrm{~F}$ ratio determined by ${ }^{19} \mathrm{~F}$ NMR are given in parentheses.

The authors demonstrated that upon performing the reaction in the presence of styrene, product $\mathbf{4 9}$ could be formed in $56 \%$, Moreover, the formation of benzylic radical species $\left(\mathrm{RCF}_{2}\right)$ was confirmed by radical trap experiment with TEMPO (intermediate 50, Scheme 48). Furthermore Stern-Volmer experiments demonstrated that the combination of 4 -HTP and TMP (1:1) quenches the excited photocatalyst. Based on these experiments the authors proposed the following mechanism, the deprotonation of 4-HTP lead to a deprotonated thiol able to quench the excited photocatalyst yielding $\mathrm{PC}^{--}$and thiyl radical. The reduced photocatalyst is oxidized by the starting trifluoromethyl arene regenerating the photocatalyst and $\mathrm{C}$ centered difluorobenzylic radical is formed upon mesolytic cleavage of fluoride from the trifluoromethyl arene radical anion (scheme 51).
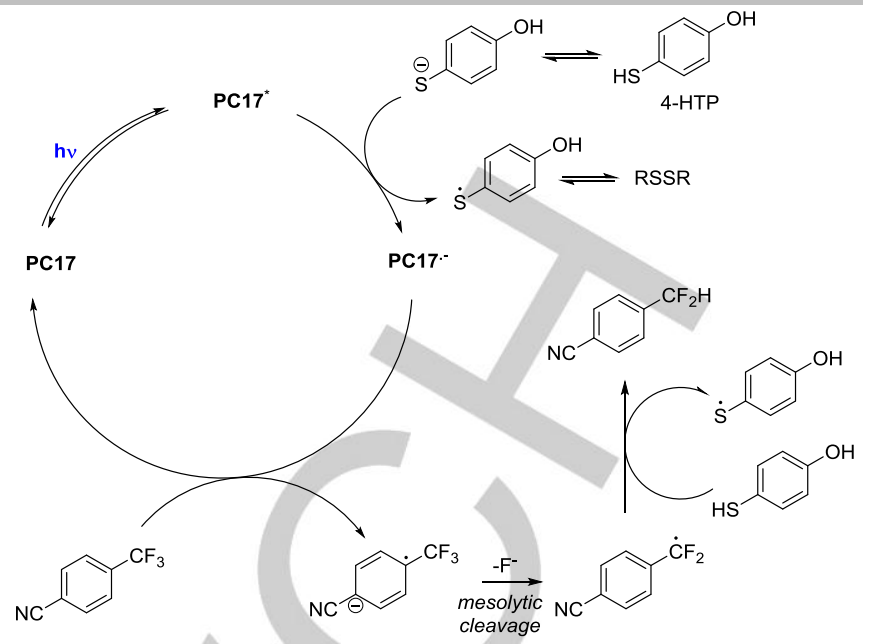

Scheme 51. Proposed mechanism for the organophotocatalytic hydrodefluorination of trifluormethylarenes.

\section{Conclusion and future directions}

This review summarizes recent applications of the use of acridinium salts and cyanoarenes in organic reactions. As discussed above, inert chemical bonds can be functionalized to introduce new bonds. Thanks to recent synthetic developments, access to a wide range of photocatalysts with tunable photophysical and electrochemical properties has allowed access to new reactivities such as the functionalization of inert bonds. Furthermore, the unique reactivity of PC2 as a super reducing agent will undoubtedly pave the way to the discovery of new transformations to replace harsh reductants. The high reactivity of cyanoarenes in a large variety of photochemical transformations shows clearly the high synthetic potential of these new photocatalyts. It is anticipated that detailed mechanistic investigations involving photophysical and ultrarapid kinetic tools will allow understanding factors controlling the reactivity of this class of photocatalysts. Lastly, developing enantioselective versions of some of the discussed reactions above will certainly be the focus of future researches in the field There is clearly a brilliant future ahead for organophotocatalysis!

\section{Acknowledgements}

The authors are grateful to the CNRS, ICBMS (UMR 5246), LHFA (UMR 5069) and the Agence Nationale de la Recherche for financial support (ANR-JCJC-2020-CDI-DEOX) and (ANR PhotoFlat $\left.\mathrm{N}^{\circ} 220424\right)$. We are also very grateful to the anonymous reviewers for the excellent comments and suggestions.

Keywords: Acridinium salts • Cyanoarenes • Photoredox • Radicals • Organophotocatalysis 
[1] http://newsletter.optics.org/1490/

[2] a) H. Yao, J. Wang, Y. Xu, S. Zhang, J. Hou, Acc. Chem. Res. 2020, 53,822-832; b) X. Wan, C. Li, M. Zhang, Y. Chen, Chem. Soc. Rev. 2020, 49, 2828-2842; c) M. Zhang, X. Guo, W. Ma, H. Ade, J. Hou, Adv. Mater. 2015, 27, 4655-4660; d) Q. Liu, Y. Jiang, K. Jin, J. Qin, J. Xu, W. Li, J. Xiong, J. Liu, Z. Xiao, K. Sun, S. Yang, X. Zhang, L. Ding, Sci. Bull. 2020, 65, 272-275.

[3] G. Ciamician, Science 1912, 36, 385

[4] a) C. S. Wang, P. H. Dixneuf, J. F. Soulé, Chem. Rev. 2018, 118, 7532-7585. b) J. M. R. Narayanam, C. R. J. Stephenson, Chem. Soc Rev. 2011, 40, 102-113. c) C. K. Prier, D. A. Rankic, D. W. C MacMillan, Chem. Rev. 2013, 113, 5322-5363. d) T. P. Yoon, M. A Ischay, J. Du, Nat. Chem. 2010, 2, 527-532. e) J. Xuan, W. J. Xiao Angew. Chemie - Int. Ed. 2012, 51, 6828-6838. f) A. Wimmer, B. König Beilstein J. Org. Chem. 2017, 14, 54-83. g) N. A. Romero, D. A Nicewicz, Chem. Rev. 2016, 116, 10075-10166. h) L. Marzo, S. K Pagire, O. Reiser, B. König, Angew. Chem. In. Ed. 2018, 57, 10034 10072; Angew. Chem. 2018, 130, 10188-10228. i) M. H. Shaw, J. Twilton, D. W. C. MacMillan, J. Org. Chem. 2016, 81, 6898-6926; j) J. Chen, Y. Li, L. Mei, H. Wu, Chin. J. Org. Chem. 2019, 39, 3040-3050 k) Y. Chen, L.-Q, Ly, D.-G. Yu, C.-J. Zhu, W.-J. Xiao, Sci. China Chem. 2019, 62, 24; I) Z. Zhang, J. H. Ye, T. Ju, L. L. Liao, H. Huang, Y. Y. Gui, W. J. Zhou, D. G. Yu, ACS Catalysis 2020, 10, 10871-10885. m) L.Marzo,K.Pagire,O.Reiser,B. Konig, Angew.Chem. Int. Ed. 2018 57,10034 -10072; Angew. Chem. 2018, 130, 10188 -10228; n) T. P. Nicholls, D. Leonori, A. C. Bissember, Nat. Prod. Rep., 2016 , 33, 12481254.

[5] D. P. Haria, B. König, Chem. Commun. 2014, 50, 6688-6699

[6] a) J. J. Molloy, T. Morack, R. Gilmour, Angew. Chem. Int. Ed. 2019, 58, 13654-13664; Angew. Chem. 2019, 131, 13789-13800; b) J. B. Metternich, R. Gilmour, J. Am. Chem. Soc. 2015, 137, 11254-11257

[7] For general reviews see: a) A. Vega-Peñaloza, J. Mateos, X. Companyó, M. Escudero-Casao, L. Dell'Amico, Angew. Chem. Int. Ed. 2021, 60, 1082-1097; Angew. Chem. 2021, 133, 1096-1111; b) Y. Lee M. S. Kwon, Eur. J. Org. Chem. 2020, 2020, 6028-6043; c) Y. Lee, M. S. Kwon, Eur. J. Org. Chem. 2020, 6028-6043.

[8] a) N. A. Romero, D. A. Nicewicz, Chem Rev, 2016, 116, 10075; b) A. Joshi-Pangu, F. Lévesque, H. G. Roth, S. F. Oliver, L.-C. Campeau, D. Nicewicz, D. A. DiRocco, J. Org. Chem. 2016, 81, 16, 7244-7249.

[9] B. Zilate, C. Fischer, C. Sparr, Chem. Commun. 2020, 56, 1767-1775.

[10] a) P. P. Singh, V. Srivastava, Org. Biomol. Chem. 2021, 19, 313-321; b) T. Y. Shang, L. H. Lu, Z. Cao, Y. Liu, W. M. He, B. Yu, Chem. Commun. 2019, 55, 5408-5419.

[11] a) S. Fukuzumi, H. Kotani, K. Ohkubo, S. Ogo, N. V. Tkachenko, H. Lemmetyinen, J. Am. Chem. Soc. 2004, 126, 1600-1601; b) T. M. Bockman, J. K. Kochi, J. Phys. Org. Chem. 1997, 10, 542-562

[12] For reviews see: a) S. Fukuzumi, K. Ohkubo, Org. Biomol. Chem. 2014 12, 6059-6071; b) K. A. Margrey, D. A. Nicewicz, Acc. Chem. Res. 2016, 49, 1997-2006.

[13] M. M. Brasholz, Acridinium Dyes and Quinones in Photocatalysis in Science of Synthesis, 'Photocatalysis in Organic Synthesis', König, Ed. Georg Thieme Verlag, Stuttgart, 2019.

[14] For the use of the Fukuzumi's photocatalyst with alkenes, see: a) X. Hu, G. Zhang, F. Bu, A. Lei, Angew. Chem. Int. Ed. 2018, 57, 1286 - 1290 Angew. Chem. 2018, 130, 1300-1304. b) L. Pitzer, F. Sandfort, F. Strieth-Kalthoff, F. Glorius, Angew. Chem. Int. Ed. 2018, 57, 16219 16223; Angew. Chem. 2018, 130, 16453-16457. c) F. Wu, L. Wang, J. Chen, D. A. Nicewicz, Y. Huang, Angew.Chem. Int. Ed. 2018, 57,2174 -2178; Angew. Chem. 2018, 130, 2196-2200. d) D. Griffin, C. L. Cavanaugh, D. A. Nicewicz, Angew. Chem. Int. Ed. 2018, 57, 5139 514; Angew. Chem. 2017, 129, 2129-2132. e) L. Wang, F. Wu, J. Chen D. A. Nicewicz, Y. Huang, Angew. Chem. Int. Ed. 2017, 56, 2097 2100; Angew. Chem. 2017, 129, 7000-7004.

[15] For the use of the Fukuzumi's photocatalyst with amines, see: a) $S$. Kato, Y. Saga, M. Kojima, H. Fuse, S. Matsunaga, A. Fukatsu, M. Kondo, S. Masaoka, M. Kanai, J. Am. Chem. Soc. 2017, 139, 2204 2207. b) J. Sim, M. W. Campbell, G. A. Molander, ACS Catalysis 2019 9, 1558-1563. c) J. B. McManus, N. P. R. Onuska, D. A. Nicewicz, J. Am. Chem. Soc. 2018, 140, 9056-9060.

[16] For the use of the Fukuzumi's photocatalyst with carboxylic acids, see a) Davies, N. S. Sheikh, D. Leonori, Angew. Chem. Int. Ed. 2017
56,13361 -13365; Angew. Chem. 2017, 129, 13546-13550. b) H. Cao, H. Jiang, H. Feng, J. M. C. Kwan, X. Liu, J. Wu, J. Am. Chem. Soc. 2018, 140, 16360-16367. c) K. C. Cartwright, J. A. Tunge, ACS Catalysis 2018, 8, 11801-11806.

[17] For the use of the Fukuzumi's photocatalyst with phosphate, see: K. A. Margrey, W. L. Czaplyski, D. A. Nicewicz, E. J. Alexanian, J. Am. Chem. Soc.2018, 140, 4213-4217.

[18] For the use of the Fukuzumi's photocatalyst with acyl silane, see: L. Capaldo, R. Riccardi, D. Ravelli, M. Fagnoni, ACS Catalysis 2018, 8, 304-309.

[19] For the use of the Fukuzumi's photocatalyst in energy transfer, see: L. Huang, M. Rueping, Angew. Chem. Int. Ed. 2020, 59, 5738 -5746; Angew. Chem. 2018, 130, 10490-10494.

[20] D. J. Wilger, J.-M. M. Grandjean, T. R. Lammert, D. A. Nicewicz, Nat Chem. 2014, 6, 720-726.

[21] J.-M. Grandjean, Anti-Markovnikov Hydrofluorination, Hydrooxysulfonylation and Hydration of Styrenes - Photoredox catalytic Polar-Radical Crossover Cycloaddition of Olefins and Allylic Nucleophiles University of North Carolina at Chapel Hill, 2014.

[22] N. A. Romero, K. A. Margrey, N. E. Tay, D. A. Nicewicz, Science 2015 349, 1326-1330.

[23] K. A. Margrey, J. B. McManus, S. Bonazzi, F. Zecri, D. A. Nicewicz, J. Am. Chem. Soc. 2017, 139, 11288-11299.

[24] W. Chen, Z. Huang, N. E. S. tay, B. Giglio. M. Wang, H. Wang, Z. Wu, D. A. Nicewicz, Z. Li, Science 2019, 364, 1170-1174

[25] K. A. Margrey, A. Levens, D. A. Nicewicz, Angew. Chem. Int. Ed. 2017, 56, 15644-15648. Angew. Chem. 2017, 129, 15850-15854.

[26] a) Y. L. Chow,W.C.Danen, S. F. Nelsen, D. H. Rosenblatt, Chem. Rev. 1978, 78,243 -274.b) F. Minisci, Synthesis 1973,1-24.

[27] J. B. McManus, D. A. Nicewicz, J. Am. Chem. Soc. 2017, 139, 2880 2883

[28] N. Holmberg-Douglas, N. P. R. Onuska, D. A. Nicewicz, Angew. Chem Int. Ed. 2020, 59, 7425-7429; Angew. Chem. 2020, 132, 7495-7499.

[29] F. Terrier, Modern Nucleophilic Aromatic Substitution; Wiley-VCH: Weinheim, 2013

[30] N. E. S. Tay, D. A. Nicewicz, J. Am. Chem. Soc. 2017, 139, 1610016104.

[31] N. Holmberg-Douglas, D. A. Nicewicz, Org. Lett. 2019, 21, 7114-7118.

[32] N. J. Venditto, D. A. Nicewicz, Org. Lett. 2020, 22, 4817-4822.

[33] C. A. Lawson, A. P. Dominey, G. D. Williams, J. A. Murphy, Chem Commun. 2020, 56, 11445-11448.

[34] N. E. S. Tay, W. Chen, A. Levens, V. A. Pistritto, Z. Huang, Z. Wu, Z. Li, D. A. Nicewicz, Nat. Catal. 2020, 3, 734-742.

[35] E. Le Saux, D. Ma, P. Bonilla, C. Holden, D. Lustosa, P. Melchiorre, Angew. Chem. Int. Ed. 2021, 60, 5357-5362.; Angew. Chem. 2021, 133, 5417-5422.

[36] a) C. Verrier, N. Alandini, C. Pezzetta, M. Moliterno, L. Buzzetti, H. B. Hepburn, A. Vega-Peñaloza, M. Silvi, P. Melchiorre, ACS Catal. 2018 8, 1062-1066; b) P. Bonilla, Y. P. Rey, C. M. Holden, P. Melchiorre, Angew. Chem Int. Ed. 2018, 57, 12819-12823; Angew. Chem. 2021, 130, 13001-13005.c) L. Buzzetti, G. E. M. Crisenza, P. Melchiorre, Angew. Chem. Int. Ed. 2019, 58, 3730-3747; Angew. Chem. 2019, 131, 3768-3786.d) D. Mazzarella, G. E. M. Crisenza, P. Melchiorre, J. Am. Chem. Soc. 2018, 140, 8439-8443.

[37] I. A. MacKenzie, L. Wang, N. P. R. Onuska, O. F. Williams, K. Begam A. M. Moran, B. D. Dunietz, D. A. Nicewicz, Nature 2020, 580,7680.

[38] A. Gini, M. Uygur, T. Rigotti, J. Alemán, O. García Mancheño, Chem. A Eur. J. 2018, 24, 12509-12514.

[39] C. Fischer, C. Kerzig, B. Zilate, O. S. Wenger, C. Sparr, ACS Catal. 2020, 10, 210-215.

[40] E. Speckmeier, T. G. Fischer, K. Zeitler, J. Am. Chem. Soc. 2018, 140, 15353-15365

[41] Q. Y. Meng, T. E. Schirmer, A. L. Berger, K. Donabauer, B. König, J. Am. Chem. Soc. 2019, 141, 11393-11397.

[42] D. Kong, M. Munch, Q. Qiqige, C. J. C. Cooze, B. H. Rotstein, R J. Lundgren; J. Am. Chem. Soc. 2021, 1432200

[43] V. Babin, A. Talbot, A. Labiche, G. Destro, A. del Vecchio, C. S. Elmore, F. Taran, A. Sallustrau, D. Audisio, ACS Catalysis 2021, 11, 29682976 
[44] T. Ju, Q. Fu, J. Ye, Z. Zhang, L. Liao, S. Yan, X. Tian, S. Luo, J. Li, D. $\mathrm{Yu}$, Angew. Chem. Int. Ed. 2018, 57, 13897-13901; Angew. Chem. 2018, 130, 14093-14097.

[45] J. Hou, A. Ee, H. Cao, H. W. Ong, J. H. Xu, J. Wu, Angew. Chem. Int Ed. 2018, 57, 17220-17224; Angew. Chem. 2018, 130, 17466-17470.

[46] Q. Fu, Z. Y. Bo, J. H. Ye, T. Ju, H. Huang, L. L. Liao, D. G. Yu, Nat. Commun. 2019, 10, 3592.

[47] B. Zhang, Y. Yi, Z. Q. Wu, C. Chen, C. Xi, Green Chem. 2020, 22 5961-5965.

[48] W. J. Zhou, Z. H. Wang, L. L. Liao, Y. X. Jiang, K. G. Cao, T. Ju, Y. Li, G. M. Cao, D. G. Yu, Nat. Commun. 2020, 11, 3263.

[49] R. Abrams, J. Clayden, Angew. Chem. Int. Ed. 2020, 59, 11600-11606; Angew. Chem. 2020, 132, 11697-11703.

[50] S. G. E. Amos, S. Nicolai, J. Waser, Chem. Sci. 2020, 11, 1127411279.

[51] N. Xu, B. Li, C. Wang, M. Uchiyama, Angew. Chem. 2020, 132, 10726 10731; Angew. Chem. 2020, 132, 10726-10731.

[52] S. Baś, Y. Yamashita, S. Kobayashi, ACS Catalysis 2020, 10, 1054610550.

[53] M. Zheng, J. Hou, L. W. Zhan, Y. Huang, L. Chen, L. L. Hua, Y. Li, W. Y. Tang, B. D. Li, ACS Catalysis 2021, 11, 542-553.

[54] A. R. Flynn, K. A. Mcdaniel, M. E. Hughes, D. B. Vogt, N. T. Jui, J. Am. Chem. Soc. 2020, 142, 9163-9168.

[55] M. Shee, S. S. Shah, N. D. P. Singh, Chem. Commun. 2020, 56, 4240 4243.

[56] C. Zhou, T. Lei, X. Z. Wei, C. Ye, Z. Liu, B. Chen, C. H. Tung, L. Z. Wu, J. Am. Chem. Soc. 2020, 142, 16805-16813.

[57] Scott, T. G. Fischer, K. Zeitler, R. Wolf, Chem. Eur. J. 2020, 26, 16374 16382.

[58] Y. Liu, X. L. Chen, X. Y. Li, S. S. Zhu, S. J. Li, Y. Song, L. B. Qu, B. Yu, J. Am. Chem. Soc. 2021, 143, 964-972.

[59] J. B. I. Sap, N. J. W. Straathof, T. Knauber, C. F. Meyer, C. F. Meyer, M. Médebielle, L. Buglioni, C. Genicot, A. A. Trabanco, T. Noël, C. W. am Ende, V. Gouverneur, J. Am. Chem. Soc. 2020, 142, 9181-9187.

[60] J. Luo, J. Zhang, ACS Catal. 2016, 6, 873-877. 


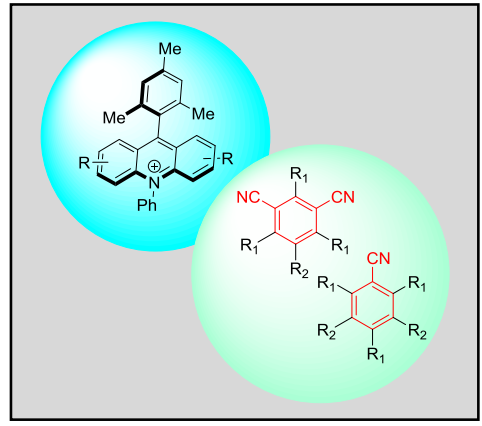

Owing to their unique reactivity in numerous challenging organic transformations, acridinium salts and cyanoarenes have become organophotocatalysts of choice in organic chemistry. This minireview discusses synthesis of those catalysts and their multireactivity with a special focus on their mechanistic aspects.

@Atlili1 and @Samilakhdar1 


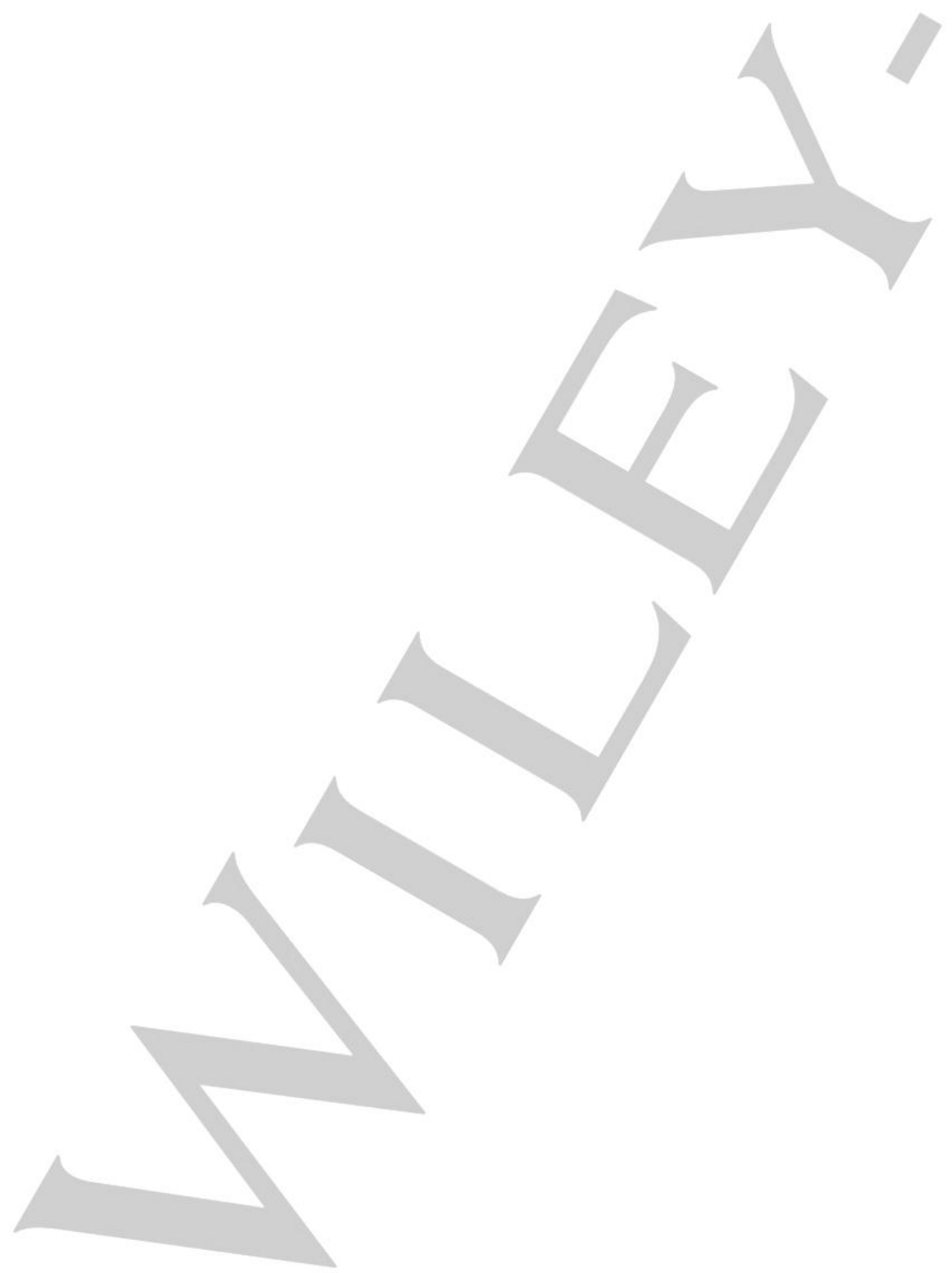

